\title{
Seasonal Marketing and Timing New Product Introductions
}

JMR, Journal of Marketing Research

Sonja Radas; Steven M Shugan;

Vol. 35, No. 3, pp. 296-315

Abstract:

A study shows how to add known seasonal patterns to any dynamic model parsimoniously, and without changing the fundamental model assumptions, illustrates how the method provides strategic implications for timing new product introductions, and provides an empirical application. The study transforms time so that, during high seasons, time is moving faster than normal time. The study also changes the product's growth along its life cycle and suggests that timing introduction decisions are dependent on the shape of the product's life cycle. 


\title{
SONJA RADAS and STEVEN M. SHUGAN*
}

\begin{abstract}
Virtually every product is seasonal; seasonality often dictates business strategy. In this article, the authors (1) show how to add known seasonal patterns to any dynamic model parsimoniously and without changing the fundamental model assumptions, (2) illustrate how their method provides strategic implications for timing new product introductions, and (3) provide an empirical application. The authors transform time so that, during high seasons, time is moving faster than normal time. Traditional methods only adjust sales, independent of the underlying sales model. The authors' method also changes the product's growth along its life cycle and suggests that timing introduction decisions are dependent on the shape of the product's life cycle. The authors' empirical work compares their theoretical results with empirical observations. With data for all major films released between July 1993 and 1995 (673 films), the authors estimate the seasonal pattern for the motion picture industry and compare

their theory with studio behavior.
\end{abstract}

\section{Seasonal Marketing and Timing New Product Introductions}

Virtually every product in every industry in every country is seasonal. Seasonality transcends products such as toys, snow shovels, and Christmas trees. Seasonality dictates business strategy in highly seasonal businesses such as accounting services, advertising, airlines, amusement parks, beauty salons, restaurants, car rentals, cinemas, communications, construction materials, education, public utilities, employment agencies, financial services, and lodging. In Tokyo, vending machines dispense only cold drinks in April and hot drinks in October. These industries exhibit regular seasonal patterns related to climatic or other periodic events.

In this article, we show how to use historic seasonal patterns. We (1) provide a method for parsimoniously adding known seasonal patterns to any dynamic model without changing the model's fundamental assumptions (e.g., parameter interpretation), (2) illustrate how that method provides strategic implications for timing product introductions (e.g., when to launch), and (3) provide an empirical application. Our method adds any known historic seasonal pattern to almost any underlying model for sales.

Not all seasonal patterns are known and predictable, but many are (see Table 1). We allow for any predictable sea-

*Sonja Radas is Assistant Professor of Marketing, Olin School of Business, Washington University (e-mail: radas@wuolin.wustl.edu). Steven M. Shugan is Russell Berrie Eminent Scholar Chair and Professor of Marketing. Warrington College of Business, University of Florida (e-mail: shugan@dale.cba.UFL.edu). The authors thank the Russell Berrie Foundation for helping finance the data collection in this article. Both authors contributed equally to this article. sonal pattern caused by exogenous factors (i.e., beyond one firm's control) such as holidays, government actions, industry traditions, weather, social phenomena, summer, and school years.

Holidays create extreme seasonality in greeting-card sales. Most retailers and distributors have their highest sales near Christmas. Confectioneries such as Suchard and Bendicks obtain $60 \%$ of their annual chocolate-mint sales during the three months before Christmas (King 1992). Sales of Smucker frozen pies are tied to the holidays.

Government actions cause financial planning booksparticularly tax-related ones-to be highly seasonal, peaking in the first quarter of the year (Schrage 1986) when tax guides are best-sellers. Tax refunds also cause seasonal upturns in durable sales.

Industry traditions also create exogenous seasonality. Sports seasons, for example, create seasonal demand for baseballs, gloves, bats, helmets, and other related products. Periodic trade shows foster seasonal activities, such as new product releases. New automotive releases create autumn demand in auto-related industries.

Weather is another cause of exogenous seasonality. Consider agricultural-related industries, travel-related businesses (e.g., ski resorts), and demand for many chemicals and fuels (e.g., natural gas). Scotts Company, the leading producer and marketer of consumer turf and lawn care products, enjoys $70 \%$ of its sales during the March and June quarters. Winter is the peak season for replacement of automobile storage batteries. Tractor Supply Company's sales peak in fiscal quarters two and four. The peak seasons for 
Table 1

EXAMPLES OF KNOWN SEASONAL PATTERNS

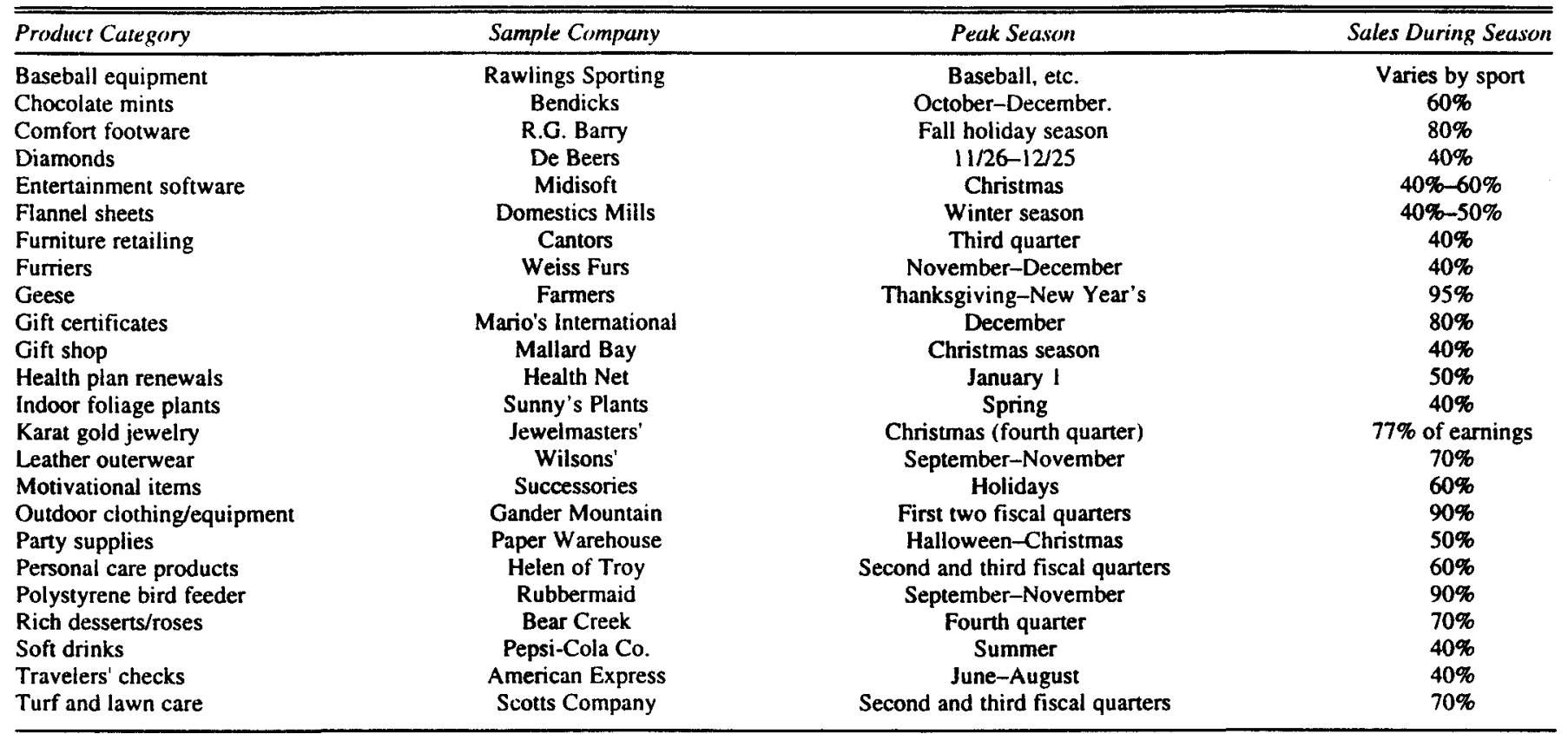

lighting products are the fall and winter, when daylight saving time ends, making days shorter. Indoor foliage plants enjoy $40 \%$ of their sales in the spring and $30 \%$ in the summer. Sales of car care items (e.g., waxes, polishes, protectants, wiper blades) peak in the spring and summer. The aspirin manufacturer Monsanto finds seasonality in acetylsalicylic acid (i.e., aspirin) sales.

Even social phenomena are often seasonal. Aggravated assaults peak and heart attacks bottom out in the summer. Triplet births and suicides both peak in the spring. Single births peak from July to September. Half of all adolescents first have intercourse between May and August. Stroke deaths for men peak from November to January, and for women from December to February. High blood pressure deaths peak from December to April and bottom out from June to August. Mania or manic episodes peak in spring and summer. Beard growth peaks in the summer and bottoms out in January.

It is surprising how concentrated sales can become during high seasons. For example, Gander Mountain Inc., a catalog and retail marketer of outdoor clothing and equipment, reports that $90 \%$ of its earnings occur in its first two fiscal quarters. Also, $90 \%$ of the shipments of Rubbermaid's injection-molded polystyrene bird feeders occur between September and November.

Seasonality is so strong in many industries that losses routinely occur in the off-season. It causes elementary and secondary textbook businesses, for example, to incur operating losses in the first two fiscal quarters.

Despite its prevalence, the impact of seasonality on marketing strategy has received little attention. Few marketing articles address this topic. Most research on seasonality is in statistics and econometrics literature. This research views seasonality as a contaminating factor and seeks to remove it from the data. Using averaging ratios or differencing, statisticians deseasonalize data by removing recurring effects found in sufficiently long time series. However, the impact of seasonal effects on strategy seldom is studied (Zellner 1979).

We argue for the study of seasonality itself because of its myriad potential applications. Many applications involve new products, such as better forecasting of introductory sales, the optimal pattern of advertising expenditures, and the timing of new product introductions.

We make a first attempt at modeling seasonality and explore some specific managerial implications for one application. We use known seasonality as valuable information in making decisions involving new product introductions, which are timed carefully to correspond to seasonal patterns (McMath 1994). The development of new products, however, often defies careful planning. Delays in completion are common, and new products are often unready for introduction during the best time. Given these delays, a firm must decide whether to launch the product if it is finished, in a nonoptimal time, or wait until the next high season. We derive conditions in which it is best to wait. We start with a new method for modeling seasonality.

\section{MODELING SEASONALITY}

We suggest that predictable external factors often cause a predictable pattern of seasonality. If that pattern is known, it should be considered when any model of sales is estimated. Although we sometimes can use the same data to estimate both the model and the seasonal pattern, this is often inefficient because we usually have substantial historic exogenous data on the seasonal pattern. Moreover, we might have insufficient data for a new product to estimate the seasonal pattem while trying to predict sales for the new product.

Our method uses this historic information on seasonality. We first estimate the historic seasonal pattem, employing the classical method of categorical variables. We, however, adopt a new approach for using that seasonal pattern. Unlike 
the traditional approach, which merely adjusts the data, independent of the underlying modei for sales, our method explicitly considers the underlying model for sales.

We deseasonalize the underlying sales model itself by transforming time. We increase the rate at which time progresses during high seasons and slow the rate during lower seasons. The stronger the season, the more rapid the increase in the rate at which time progresses. Therefore, in addition to adjusting for the strength of the season, our approach also speeds or slows the product's aging along its life cycle. During a high season, a product ages faster than during a low season.

This view of seasonality offers many advantages. It directly considers the sales curve for a product $S(t)$. It provides a parsimonious way of adding known seasonal patterns into any dynamic model without changing the fundamental assumptions of the model $S(t)$. It allows seasonality in early periods to affect sales in later periods. It also allows the derivation of managerial implications for known seasonality patterns. We assume $S(t)$ is specified correctly.

By transforming time, the model without seasonality, namely, $S(t)$, remains the same. Seasonality merely changes the time each sale occurs. In a high season, the product enjoys sales it would have had in later periods. After the high season, the product's sales suffer but only by the amount shifted to the high seasons. Thus, the fundamental model of sales remains the same in a transformed-time dimension.

During off-season time slows, some buyers stop buying, and the product moves more slowly through its life cycle. For example, people see films throughout the year and remain in the market the entire year. However, the week after Christmas might be equivalent to the preceding three weeks.
One month during the peak season equals several months off-season.

To explain the time transformation method, we define the function $g(t)$. This function captures the known seasonal patterns in normal (i.e., observed) time. When known, $g(t)$ provides valuable input for strategic decisions. We can measure $g(t)$ in any unit, including attendance, unit sales, or dollar sales. In Figure 1 we provide $g(t)$ in monthly attendance at Disney World (Sehlinger 1995). In Table 1, we provide other examples.

We define $f(t)$ as transformed time, abbreviated $T=f(t)$. This function accelerates time during high seasons. The duration of a seasonal cycle, in transformed time, equals the duration in observed time. When the seasonal pattem repeats each year, for example, transformed time and observed time equate at the end of each year. Equation 1 defines transformed time accordingly. Here, $\mathrm{N}$ is the number of periods in the seasonal cycle, and $\mathrm{K}$ is a constant. Note that $\mathrm{T}$ is in the same units as $\mathrm{N}$ :

$$
T=f(t)=K \int_{0}^{t} g(u) d u,
$$

where

$$
K=\frac{N}{\int_{0}^{N} g(u) d u}
$$

For example, suppose $g(t)=1+\cos (t \times \pi / 6)$, as is shown in Figure 2, Part A. Here, $g(t)$ cycles, repeating every 12 months (i.e., $N=12$ ), and peaks during months $0,12,24$, and so on. Winter resorts display this seasonal pattern, bot-

Figure 1

ATTENDANCE AT DISNEY WORLD BY MONTH

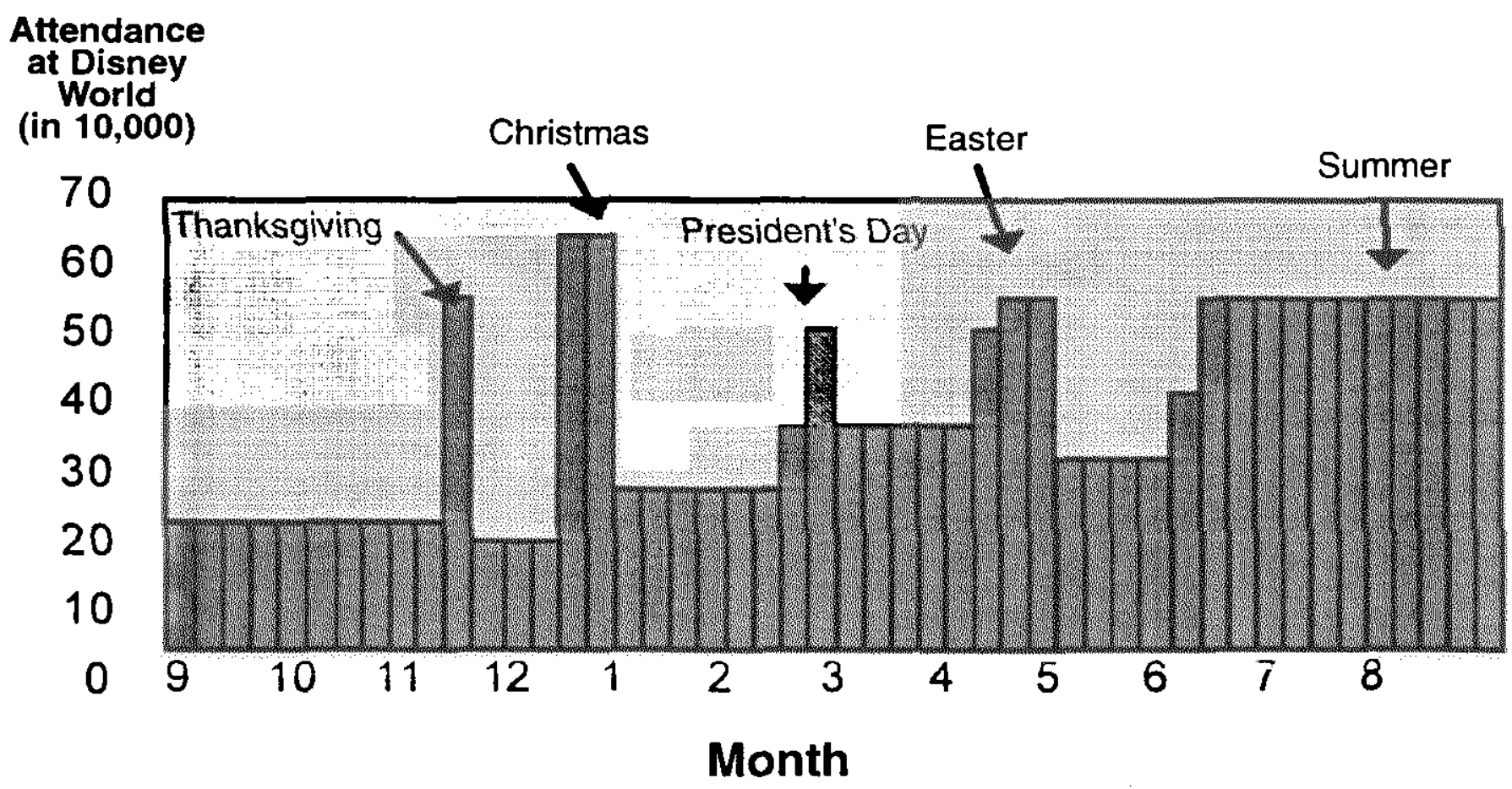


Figure 2

SEASONALITY AND TRANSFORMED TIME BY OBSERVED TIME

\section{A: Seasonality Pattern}

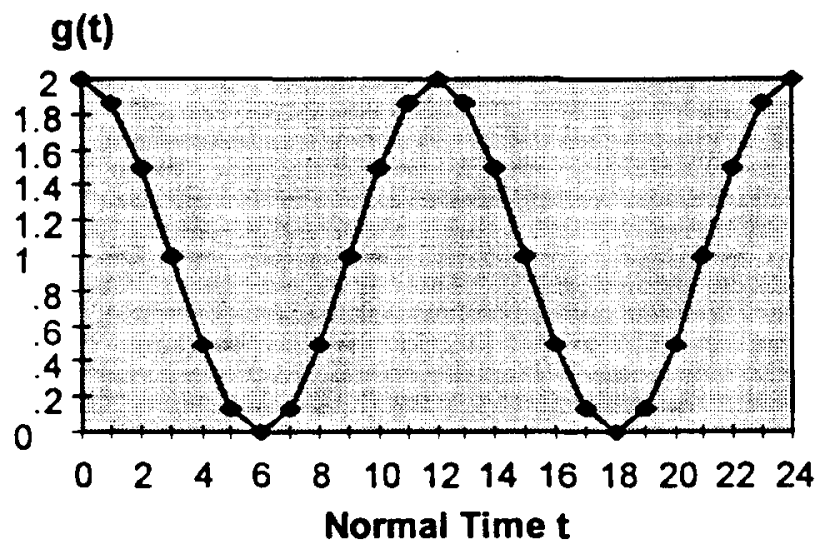

\section{B: Transformed Time}

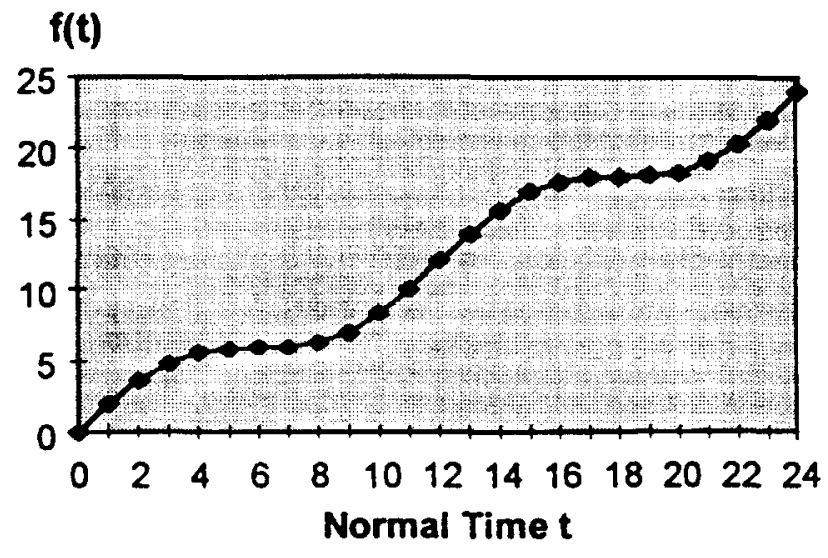

toming during months 6,18 , and so on. During months 1 to 3 , transformed time moves faster than observed time. During months 4 to 8 , transformed time moves slower than observed time.

For this $g(t)$, Equation 2 provides $f(t)$ because $K=1$. Here, transformed time, $f(t)$, equals observed time $t$ at the beginning of every cycle (i.e., $0,12,24,36, \ldots$ ). See Figure 2, Part B.

$$
f(t)=(6 / \pi) \sin (t \times \pi / 6)+t .
$$

We now define the following notation, where $S(t)$ is any dynamic model of sales over time t. Let

$$
\begin{aligned}
Y(t)= & \text { cumulative sales to observed or normal time } t ; \\
S(t)= & \text { observed sales in observed time, by definition, } S(t)= \\
& d Y(t) / d t ; \\
Y_{T}(T)= & \text { cumulative sales to transformed time } T \text {; and } \\
S_{T}(T)= & \text { sales in transformed time, by definition, } S_{T}(T)= \\
& d Y_{T}(T) / d T .
\end{aligned}
$$

Note that observed cumulative sales in observed time always equals cumulative sales in transformed time, because $\mathrm{Y}(\mathrm{t})=\mathrm{Y}\left\{\mathrm{f}^{-1}[\mathrm{f}(\mathrm{t})]\right\}=\mathrm{Y}\left[\mathrm{f}^{-1}(\mathrm{~T})\right]=\mathrm{Y}_{\mathrm{T}}(\mathrm{T})$. So, $\mathrm{Y}(\mathrm{t})$ $=Y_{\mathrm{T}}(\mathrm{T})$ everywhere. Moreover, $\mathrm{S}(\mathrm{t})=\mathrm{d} \mathrm{Y}(\mathrm{t}) / \mathrm{dt}$, so $\mathrm{S}(\mathrm{t})=$ $S_{T}[f(t)] \times f^{\prime}(t)$. Solving, we get Equation 3, which provides deseasonalized sales ${ }^{l}$ in transformed time.

$$
S_{T}[f(t)]=\frac{S(t)}{f^{\prime}(t)}
$$

\section{Comparison with the Traditional Approach}

Note that both the transformed-time approach and the traditional approach adjust observed sales by a seasonal adjustment, which is independent of the sales function $S(t)$. However, the transformed-time approach also considers the

IWe thank an anonymous reviewer for noting that when $S(t)$ is only a function of $Y(t)$, as it is for diffusion models. $S(t)=f^{\prime}(t) \phi[Y(t)]$, where the function $\phi[Y(t)]$ is independent of $f(t)$. Thus, observed sales can be fitted as a multiplicative model. underlying model of sales $S(t)$. It suggests that seasonality also alters the aging of the product. High seasons make aging more rapid and move the product faster along its life cycle. Low seasons slow aging and decrease the progression along the life cycle.

For example, if a new product enters a high season during the early growth stage of its life cycle, seasonality would both increase observed sales and accelerate growth. Entering a high season during the decline stage of a life cycle, in contrast, would temporarily increase sales but accelerate the decline of the product as it more quickly exhausts its market. With the transformed-time method, the impact of seasonality depends on the position in the life cycle, namely, $S(t)$.

Unlike the traditional approach, we explicitly consider the underlying sales function. We go beyond merely removing seasonality from the underlying data. The traditional method adjusts the data by dividing by a normalized $\mathrm{g}(\mathrm{t})$. In that case, deseasonalized sales, denoted $S_{D}(t)$, become $S_{D}(t)=S(t) / f^{\prime}(t)$, where $S(t)$ is observed sales at time t. Note that, unlike Equation $3, S_{D}(t)$ is only a function of $f^{\prime}(t)$ and $S(t)$. When the high season is twice as strong, for example, the traditional approach simply divides sales by two.

To be precise, in the transformed-time approach, $\mathrm{Y}_{\mathrm{T}}[\mathrm{f}(\mathrm{t})]=$ $Y(t)$, so $Y_{T}(t)=Y[h(t)]$, where $h(t)=f^{-1}(t)$, as in Lemma 1 :

Lemma 1: At observed time $t$, deseasonalized sales are $S_{D}(t)=$ $\mathrm{S}(\mathrm{t}) / \mathrm{f}{ }^{\prime}(\mathrm{t})$ in the traditional approach, and $\mathrm{S}_{\mathrm{T}}(\mathrm{t})=$ $S[h(t)] h^{\prime}(t)$ in the transformed-time approach, where $h(t)=f-l(t)$.

Note that the traditional approach deseasonalizes sales by adjusting observed sales, that is, dividing by $f^{\prime}(t)$. The transformed-time approach, however, deseasonalizes sales by also shifting the product along its life cycle, that is, $\mathrm{S}[\mathrm{h}(\mathrm{t})]$, in addition to adjusting sales, that is, multiplying by $h^{\prime}(t)$. Entering a high sales season accelerates growth along the life cycle, whereas entering a low sales season decelerates it. 


\section{Discrete Approximation}

Although $\mathrm{S}(\mathrm{t})$ is continuous, data are discrete. For a discrete approximation, let $\mathrm{f}^{\prime}(\mathrm{t})=\mathrm{f}(\mathrm{t})-\mathrm{f}(\mathrm{t}-1)$. Equation 4 deseasonalizes discrete sales, where $s(t)$ and $s_{T}(T)$ are discrete sales in normal and transformed time, respectively:

$$
s_{T}[f(t)]=\frac{s(t)}{f(t)-f(t-1)}
$$

For example, consider the sales in Figure 3, Part A, and Table 2 with the seasonal 12 month cycle $g(t)$ from Figure 2. Sales $s(t)$ increase until $t=2$, decrease until $t=6$, and then rapidly increase until $\mathrm{t}=12$.

Equation 4 produces $s_{T}(T)$ in transformed time, as is shown in Figure 3, Part B. Table 2 shows our computations. We divide the data points for sales in observed time, $s(t)$, by $f(t)-f(t-1)$, to obtain sales in transformed time, $s_{T}(T)$. The points in observed time are spaced equally, whereas the points in transformed time are spaced according to $f(t)$. Points are closer together during the low season because time is moving more slowly; a transformed month is several normal months. In transformed time, for example, June consists of three normal months. When $f(t)-f(t-1)=1$, the spacing in observed time and transformed time are equal.

Cumulative sales are equal for each time line. For example, in Figure 3, the shaded areas under the first four data points are equal for observed and transformed time. Observed time period 3 corresponds to transformed time 4.91. Thus, Part A's shaded area to month 3 and Part B's to month 4.91 equate.

With the new spacing, the sales in transformed time displays a simple linear growth (Figure 3), concealed by seasonality. For an annual pattern, after each 12-month cycle, transformed time equals observed time. Continuous cumulative normal and deseasonalized sales always equate.

Figure 3

SALES BY TIME


Table 2

EXAMPLE OF TRANSFORMED-TIME APPROACH

\begin{tabular}{|c|c|c|c|c|c|c|c|}
\hline$t$ & $g(t)$ & $T=f(t)$ & $f(t)-f(t-t)$ & $s(t)$ & $s_{T}(T)$ & $\begin{array}{l}\text { Traditional } \\
\text { Approach }\end{array}$ & $\begin{array}{c}\text { Transformed-Time } \\
\text { Approach }\end{array}$ \\
\hline 0 & 2.00 & 0.00 & 0.00 & 0.00 & 0.00 & $(0,0.00)$ & $(0,0.00)$ \\
\hline 1 & 1.87 & 1.95 & 1.95 & 76.43 & 39.10 & $(1,39)$ & $(1.95 .39)$ \\
\hline 2 & 1.50 & 3.65 & 1.70 & 124.17 & 73.08 & $(2,73)$ & $(3.65 .73)$ \\
\hline 3 & 1.00 & 4.91 & 1.26 & 123.32 & 98.20 & $(3,98)$ & $(4.91,98)$ \\
\hline 4 & .50 & 5.65 & .74 & 84.15 & 113.08 & $(4,113)$ & $(5.65,113)$ \\
\hline 5 & .13 & 5.95 & .30 & 35.84 & 119.10 & $(5,119)$ & $(5.95,119)$ \\
\hline 6 & .00 & 6.00 & .05 & 5.41 & 120.00 & $(6,120)$ & $(6.00,120)$ \\
\hline 7 & .13 & 6.05 & .05 & 5.45 & 120.90 & $(7,121)$ & $(6.05 .121)$ \\
\hline 8 & .50 & 6.35 & .30 & 38.20 & 126.92 & $(8,127)$ & $(6.35,127)$ \\
\hline 9 & 1.00 & 7.09 & .74 & 105.52 & 141.80 & $(9,142)$ & $(7.09,142)$ \\
\hline 10 & 1.50 & 8.35 & 1.26 & 209.63 & 166.92 & $(10.167)$ & $(8.35,167)$ \\
\hline 11 & 1.87 & 10.05 & 1.70 & 341.34 & 200.90 & $(11,201)$ & $(10.05,201)$ \\
\hline 12 & 2.00 & 12.00 & 1.95 & 469.18 & 240.00 & $(12,240)$ & $(12.00 .240)$ \\
\hline
\end{tabular}


Therefore, seasonality influences transformed time $\mathrm{T}$ through the function $g(t)$. Different seasonal patterns produce different transformed times. In transformed time, no seasons exist. In this example, $g(t)>1$ implies a high season (transformed time is moving faster than observed time); $\mathrm{g}(\mathrm{t})<1$ implies a low season (transformed time is moving slower); and when $g(t)=1$, transformed time is moving at the speed of observed time. In the special case in which $g(t)$ is constant, there are no seasons.

Although we emphasize using $f(t)$ for strategic implications, it also gives us improved predictive accuracy. For example, Figure 4 shows early box office returns for two films released in late April: Fine Line's Naked in New York and Miramax's Picture Bride. Growth appears evident, until we consider seasonality. Here, Memorial Day weekend (5/27) dramatically distorts real growth. The empirical section of this article shows that our transformed-time model, by considering seasonality, provides much better predictions than a nonadjusted forecast or traditional methods of adjustment.

\section{TIMING NEW PRODUCT INTRODUCTIONS}

In this section, we explore an application of our transformed-time method. Space limitations allow only one application, the timing of new product introductions. Many firms time these introductions to correspond with the beginning of their peak selling season. Cadbury, for example, times new confectionery introductions for the Easter selling season. Given expected development times, Cadbury starts developing new products exactly 18 months before the peak Easter season. Unfortunately, development times are often difficult to predict, and delays often occur in the completion of new products. We consider the problem of whether to wait until the peak season when the new product is ready for launch during the off-season.

When delays occur, firms sometimes wait until the following high season. Campbell Soup's new line of ready-to- serve Home Cookin' soups, for example, experienced production delays. The line was ready only at the tail end of the highly seasonal soup market. Campbell waited almost a year to introduce the new line.

Production delays are also common in the movie industry. Production delays prevented Disney from releasing its animated film The Lion King during the peak Christmas season. Disney decided to wait until the next peak, namely, summer, for that movie but did not wait to launch its film D2: The Mighty Ducks.

With production delays, the James Bond film Golden Eye missed the desirable summer season. Of the 16 James Bond films, MGM/UA has released the majority during the summer months (Ulmer 1994). With more than $\$ 50$ million invested in Golden Eye, MGM/UA waited until the subsequent high season, Thanksgiving 1995.

Production problems, special effects problems, censors, public complaints, lawsuits, and other unforeseen events cause delays. Worrisome test results, suggesting the need for additional editing, forced Paramount to delay its planned Christmas release of the film Intersection. Other recent delayed releases include Johnny Mnemonic, Blue Sky, The Quick and the Dead. The Last of the Mohicans. Demolition Man. Wolf, The River Wild, Natural Born Killers, Car 54 , Scarface, True Lies, I'll Do Anything, Guarding Tess, and House of Spirits.

When a new product enters the market at the beginning of a high season, greater revenues and profits are possible. When delays occur, the production firm might miss the critical season. The firm must decide whether to wait for the next high season, launch immediately, or wait for some intermediate time. Waiting provides potentially larger sales but in the distant future. The same problem occurs when development finishes early.

These decisions are especially critical in the movie industry, which spends tens of millions of dollars on production

Figure 4

BOX OFFICE BY WEEK

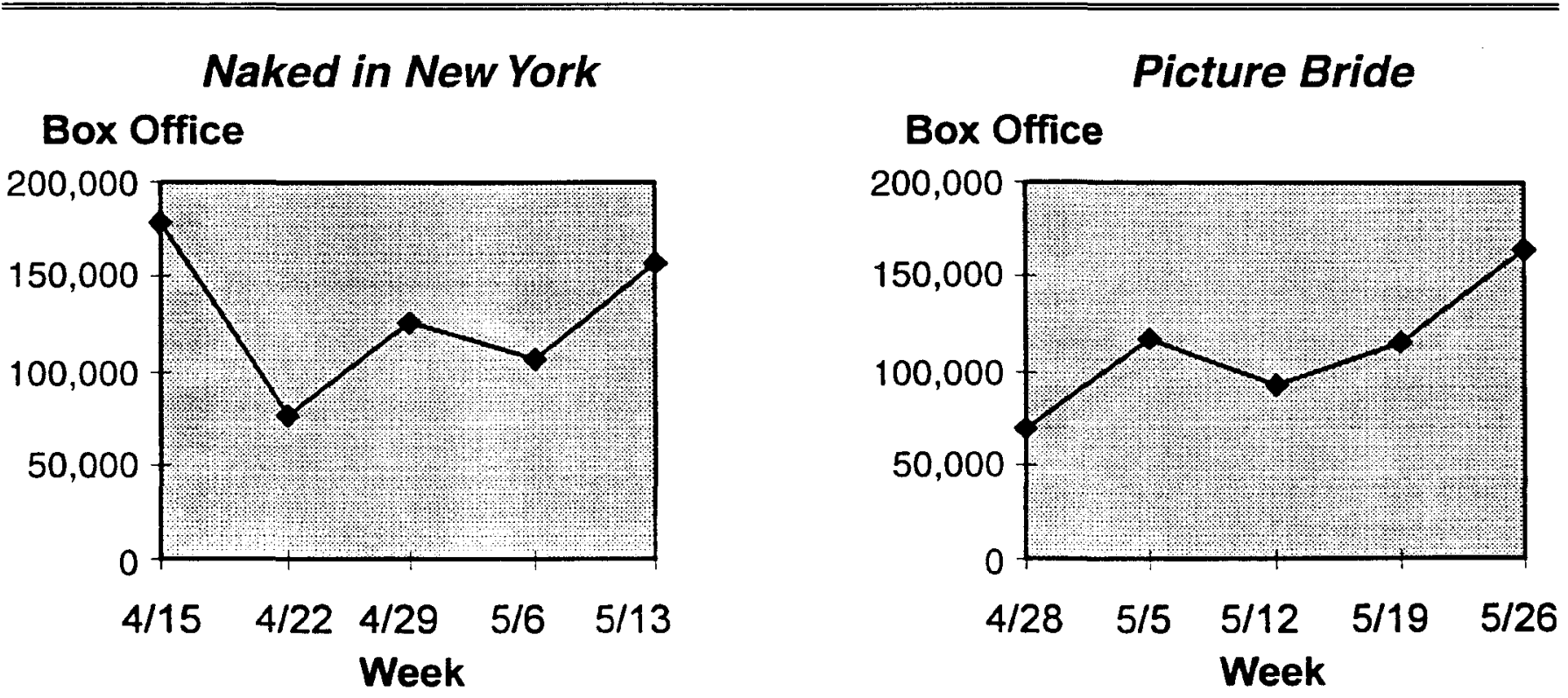


schedules with planned December releases. A one-month delay in production could completely miss the Christmas season. With many films grossing more than $\$ 50$ million, a five-month delay to the summer season has an opportunity cost of more than $\$ 2$ million.

\section{The Problem}

We start by considering exponential sales with a simple seasonal pattern consisting of an off-peak season, ${ }^{2} \mathrm{~g}(\mathrm{t})=$ $k \alpha_{1}$ for $t<t_{s}$, followed by a peak season, $g(t)=k \alpha_{2}$ for $t \geq$ $t_{s}$. We define the constant $k$ so that $f(t)=\alpha_{1} t$ for $t_{s}>t \geq 0$ and $f(t)=\alpha_{1} t_{s}+\alpha_{2}\left(t-t_{s}\right)$ for $t \geq t_{s}$.

We have just completed a new product. We can launch now with no wait $(w=0)$, wait a short time $\left(w<t_{s}\right)$, or wait until the peak season $\left(w=t_{s}\right)$. We seek the optimal wait, $w^{*}$.

The seasonal pattern, as well as the model parameters themselves, are independent of the launch date. This independence allows parsimony, but it could be a poor approximation of reality if a very strong product actually changes the industry seasonality pattern.

Now we consider the launch decision. Launching immediately implies a seasonal pattern with transformed time $f(t)$. Waiting produces transformed time $f_{w}(t)$, where, by definition, $f_{w}(t)=f(t+w)-f(w)$.

For example, suppose a product is ready on March 1. We could wait until the high season beginning Memorial Day, 12 weeks away. Here, $w=12$, and $f_{w}(t)=f(t+12)-f(12)$. Therefore, $f(t)$ is the current transformed time function, and $\mathrm{f}_{\mathrm{w}}(\mathrm{t})$ is transformed time starting at Memorial Day.

Waiting is better only when its benefits outweigh the loss inflicted by the discount rate, $r$. Therefore, for a wait to be optimal (i.e., $w^{*}>0$ ), the product must capture more sales during the high season than when $w^{*}=0$. The seasonal pattern determines the magnitude of these additional sales.

\section{Exponential Sales}

We develop timing implications for two dynamic models of sales: exponential (i.e., monotonic sales) and classic diffusion (i.e., quadratic sales). The exponential model describes the vast majority of motion pictures; the diffusion model describes many durables.

Equation 5 provides the exponential sales model, where $\gamma$ and $\beta$ are constants. Constant $\gamma$ represents the initial level of sales, whereas $\beta$ captures the curvature of the sales function:

$$
S_{T}(T)=\gamma e-\beta T .
$$

Equation 6 provides cumulative sales, $Y_{T}(T)$, where by definition, $Y_{T}(T)=\int_{0}^{T} S_{T}(\tau) d \tau$ :

$$
Y_{\mathrm{T}}(\mathrm{T})=(\gamma / \beta)\left(1-e^{-\beta T}\right)
$$

Recalling that $Y(t)=Y_{T}(T)$ and $T=f(t)$, we obtain cumulative sales in observed time with seasonality:

$$
Y(t)=(\gamma / \beta)\left[1-e^{-\beta f(t)]} .\right.
$$

Solving for $S(t)$ yields Equation 8:

$$
S(t)=\gamma^{\prime}(t) e-\beta f(t) .
$$

\footnotetext{
${ }^{2}$ Although this seasonal pattern might be appropriate for products with short lives, we might need to extend the analysis to more complex seasonal patterns when the product has a much longer life.
}

Equation 8 provides sales with seasonality in observed time. This model retains the parameter interpretations of the original model and the interpretations of the parameters. For example, $\gamma$ and $\beta$ are independent of $t$, making the new model parsimonious and loyal to the original theory of sales. We also can interpret $\gamma / \beta$ as the market potential (i.e., cumulative sales as $\mathrm{t} \rightarrow \infty$ ), denoted by $\mathrm{m}$, in both models.

In observed time, exponential sales curves can take only the single-peaked shape. In transformed time, however, the exponential model can capture more general shapes.

\section{Endogenously Determined Life}

Let $\mathrm{L}$ denote the product's life. Our empirical work finds that the average life of a film is 9.6 weeks. Many new products exhibit limited fixed lives. Retailers, for example, might allow fashion items a limited fixed life before applying deep markdowns and discontinuation. Most films aiso have fixed lives for the studio. Motion picture studios and their distributors sign contracts with exhibitors for a fixed length of time. Although exhibitors might have an option to extend the film's life, studios obtain a much smaller percentage of the box office during the extended period. Generally, retailers and exhibitors have alternative uses for shelf space. They consequently drop products that still enjoy some sales. Many firms therefore delay new product introductions to avoid early deaths.

For other products, however, the life of the product might be determined endogenously by its sales, because the retailer drops the product when sales fall below some critical level c. In this section, we consider an endogenous life, in which the product stays on the market provided that sales remain above some cutoff level $\mathrm{c}$. When sales fall below $\mathrm{c}$, the retailer or exhibitor drops the product. For this situation, we obtain Theorems 1 and 2. See the Appendix for proofs.

Theorem 1: If the product is dropped when discounted sales fall below cutoff $c$, then the product's life equals $L$, where

$$
L=\frac{\ln \frac{\gamma}{c}+\left[\beta\left(\alpha_{2}-\alpha_{1}\right)-\alpha_{1} \beta w\right]}{r+\alpha_{2} \beta} .
$$

Note that as $r$ and $\beta$ increase, we drop the product sooner because discounted sales drop more quickly. As the off season becomes stronger, that is, as $\alpha_{2}-\alpha_{1}$ decreases, the product's life increases because, as we see from Theorem 2, we launch the product during the off season.

Theorem 2: When the product's life is endogenous, it should be launched immediately.

Theorem 2 is a strong result. It says we should never wait for the season when the product's life is determined endogenously. After consideration, the result is intuitive. When the life is endogenous, the product enjoys a longer life during the off-peak season because the discounted sales during the season quickly drop below the cutoff.

Although Theorem 2 has the same cutoff for the peak and off-peak seasons, many retailers or exhibitors have a higher cutoff during the peak season because of opportunities with competitive products. The higher cutoff strengthens the results of Theorem 2 and provides a greater incentive for an immediate launch. 


\section{Exogenous Life L}

A fixed exogenous life $L$ complicates the situation. Here, the product has the same life during the peak and off-peak season but far fewer sales off-season. The launching decision must compare some sales now against greater sales later. Motion pictures studios, for example, face this decision. The studios sign contracts with exhibitors that give them a large share of the profit for only the first few weeks (usually $90 \%$ in the first week, $70 \%$ in the second, and $60 \%$ in the third). After the initial life, the exhibitor enjoys most of the profit. The contracts are the same regardless of the time of release, causing studio profits to come mostly during the first few weeks. Thus, from the studio's viewpoint, the movie's life is fixed. With fixed L, some strategies never work:

Lemma 2: Given exogenous life $\mathrm{L}$ and the peak season beginning at $t_{\mathrm{s}}$,

(a) if $L<t_{s}$, profits are declining for any delay up to $w=t_{s}-L$ and

(b) for any $L$, if the peak-season is flat and $w>t_{s}$, profits are declining.

Lemma $2 \mathrm{a}$ notes that, when a product's life is short, $\mathrm{L}<$ $t_{s}$, it enjoys no advantage for nonzero waits less than $t_{s}-L$. The tail of the life cycle fails to reach the season, so discounting always reduces profits. Lemma $2 b$ notes that the product enjoys no advantage by waiting longer than $t_{s}$, because all of the product's life cycle is already in the peak season when $w=t_{s}$.

We are left with three possible strategies. First, we can launch immediately, $w=0$, and enjoy sooner but smaller sales. Second, we can wait until only the tail end of the life cycle enters the peak season, $t_{s} \geq w \geq t_{s}-L$. Third, we can wait until the start of the peak season, $w=t_{s}$, and enjoy greater but postponed sales. Here, the tail of the product's life cycle might extend into the peak season, allowing greater sales than an immediate launch. We consider these three strategies with Theorems 3, 4, and 5, respectively. We begin by considering the optimal wait.

The best strategy depends on many factors, including the time until the peak season, the discount rate, the shape of the sales curve, the way seasonality changes that shape, and the length of the life. To find the best strategy, we maximize profits, given by Equation 9 with respect to $w$, where $C$ are fixed costs:

$$
\begin{aligned}
\pi(w) & =\gamma \int_{w}^{t} e^{-r t} \alpha_{1} e^{-\beta \alpha_{1}(t-w)} d t \\
& +\gamma \int_{t s}^{L+w} e^{-r t} \alpha_{2} e^{-\beta\left(\alpha_{2} t+\left(\alpha_{1}-\alpha_{2}\right) t_{s}-\alpha_{1} w\right.} d_{d t}-C \\
& =\frac{\alpha_{1} \gamma}{r+\alpha_{1} \beta} e^{\alpha_{1} \beta w}\left[e^{\left(r+\alpha_{1} \beta\right) w}-e^{\left(r+\alpha_{1} \beta\right) t s}\right] \\
& \left.+\frac{\alpha_{2} \gamma e^{-\beta}\left[t_{s}\left(\alpha_{1}-\alpha_{2}\right)-\alpha_{1} w\right.}{r+\alpha_{2} \beta}\right] \\
& {\left[e^{-\left(r+\alpha_{2} \beta\right) t_{s}}-e^{-\left(r+\alpha_{2} \beta\right)(L+w)}\right]-C . }
\end{aligned}
$$

Equation 10 provides the derivative of profit function:

$$
\frac{d \pi}{d w}=K\left[-A e^{-a w}+B+e^{-(a+b) w}\right]
$$

where the constants A, B, a, and b are defined as follows:

$$
\begin{gathered}
A=\frac{\alpha_{1}}{\alpha_{2}} \frac{r}{\left(r+\alpha_{1} \beta\right)\left[r+\beta\left(\alpha_{2}-\alpha_{1}\right)\right]} e^{\alpha_{2} \beta\left(L-t_{s}\right)} e^{r L} \\
\\
{\left[\left(r+\alpha_{2} \beta\right) e^{\alpha_{1} \beta t_{s}}\right], a=r+\alpha_{1} \beta,}
\end{gathered}
$$

and

$$
\begin{gathered}
\text { B }=\frac{\alpha_{1}}{\alpha_{2}} \frac{r}{\left(r+\alpha_{1} \beta\right)\left[r+\beta\left(\alpha_{2}-\alpha_{1}\right)\right]} e^{\alpha_{2} \beta\left(L-t_{s}\right)_{e} r L} \\
{\left[\beta\left(\alpha_{2}-\alpha_{1}\right) e^{-\pi_{s}}\right], b=\left(\alpha_{2}-\alpha_{1}\right) \beta .}
\end{gathered}
$$

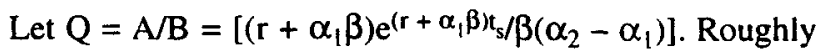
speaking, $Q$ represents the advantage of an immediate launch over waiting. Larger values for $Q$ favor an immediate launch. Theorem 3 presents the implications for the first strategy, launching now:

Theorem 3: (a) The product should be launched immediately for sufficiently large base demand, $\alpha_{1}$, sufficiently small seasonal effect, $\alpha_{2}-\alpha_{1}$, and sufficiently large time to the season, $t_{\mathrm{s}}$. (b) The product should be launched immediately for sufficiently large or small $\beta$. Waiting is only optimal for a medium $\beta$.

Theorem $3 \mathrm{~b}$ is interesting. It suggests that when most of the product's sales are early in its life, its launch should be immediate. Moreover, when most of the product's sales are late in its life, it should also launch immediately. However, intermediate cases favor waiting for the peak season.

The shape of the sales curve provides the support underlying this interesting result. Remember that the peak season accelerates sales, moving sales forward. Therefore, when $\beta$ is large, there is less advantage to accelerating sales because off-peak sales already occur early in the product's life. With less advantage, discounting favors an immediate launch. When $\beta$ is small, the seasonal acceleration is less pronounced because the sales stretch into the distant future. With less pronounced acceleration, we launch immediately. With intermediate levels of $\beta$, however, we must compromise between the benefit of accelerated sales in the high season and the cost associated with discounting.

Now we consider the second strategy, waiting for $w^{*}=z$, where $t_{s} \geq z \geq t_{s}-L$. Here, $z$ is a unique maximum of the profit function, computed numerically from $d \pi / d w=0$.

Theorem 4: Let $a_{1}=r+\alpha_{1} \beta$ and $a_{2}=r+\alpha_{2} \beta$. The optimal delay is always 0 or $t_{s}$, except in the following cases in which it is possible to have optimal intermediate delay:

(a) When $L \geq t_{s}$ and 


$$
\begin{gathered}
a_{2} L+\ln a_{1}>\ln \frac{\alpha_{2} a_{1}\left(r+a_{2}-a_{1}\right)}{\alpha_{1} r} \\
>a_{2}\left(L-t_{s}\right)+\ln \left[e^{a_{1} t_{s} a_{2}-\left(a_{2}-a_{1}\right)}\right]
\end{gathered}
$$

then the optimal delay is either $\mathrm{t}_{\mathrm{s}}$ or $\mathrm{z}$.

(b) When $\mathrm{L}<\mathrm{t}_{\mathrm{s}}$ and

$$
\begin{aligned}
& a_{2} L+\ln a_{1}>\ln \frac{\alpha_{2} a_{1}\left(r+a_{2}-a_{1}\right)}{\alpha_{1} r} \\
& >\ln \left[e^{a_{1}{ }^{\prime} a_{2}}-\left(a_{2}-a_{1}\right)\right] \text {, }
\end{aligned}
$$

then the optimal delay is either $0, t_{s}$, or $z$.

Conditions $\mathrm{a}$ and $\mathrm{b}$ in Theorem 4 are rare because of the monotonic nature of the tail of the exponential function. As the tail moves into the season, in-season sales increase at an increasing rate. Therefore, when it is optimal to have any portion of the tail in the season, it becomes optimal to move all of the tail into the season. Subsequently, we show that when the tail is not monotonic, that is, the sales curve possesses a maximum, it might be best to wait only until the peak of the life cycle enters the season. For monotonic sales, however, condition b is rarely best (see Figure 5).

Figure 5 shows the projected sales curve for a new product launched at three different times: $0, w<t_{s}$, and $t_{s}$. Launching at time 0 produces smaller initial sales with a less rapid decline than introducing at the start of the season $t_{s}$. Launching at an intermediate time $w<t_{s}$ produces the same sales curve as an immediate launch until the high season. At that point, the product enjoys a boost in sales but a more rapid rate of decline. However, if waiting until $w$ is prof-

Figure 5

PROJECTED SALES CURVES FOR NEW PRODUCT

\section{Sales}

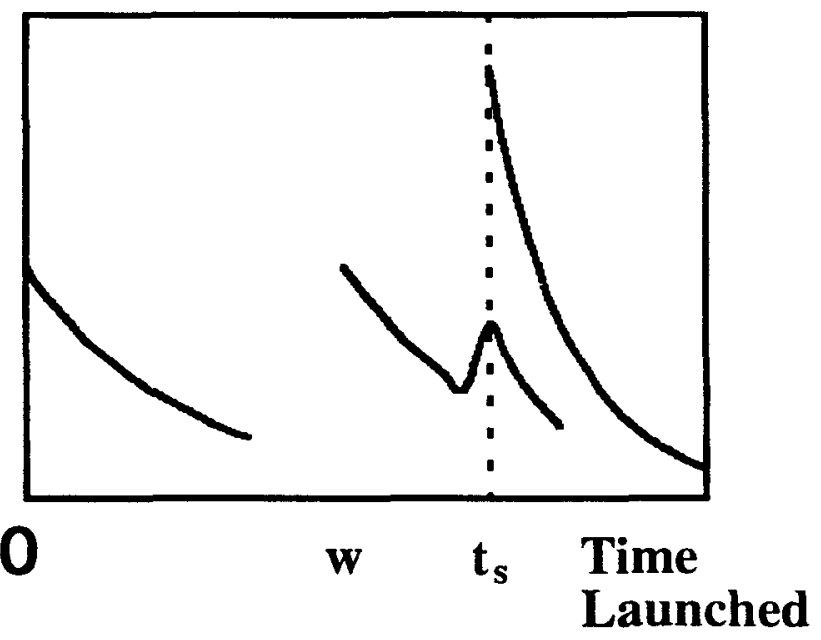

itable, a much larger sales boost occurs by waiting until $t_{s}$. Therefore, intermediate waits $0<\mathrm{w}<\mathrm{t}_{\mathrm{s}}$ are seldom optimal. We end this section with sufficient conditions for the optimality of the third and final strategy, waiting until the start of peak-season:

Theorem 5: (a) The optimal strategy is to wait until the peak season, $w^{*}=t_{s}$, whenever $A e^{-a x} \geq B+e^{-(a+b) x}$, where $x=\max \left\{0, t_{s}-L\right\}$, and

$$
\begin{gathered}
\frac{\alpha_{1}}{\left(r+\alpha_{1} \beta\right)}\left[1-e^{-\left(r+\alpha_{1} \beta\right) t_{s}}\right] \\
\leq \frac{\alpha_{2}}{\left(r+\alpha_{2} \beta\right)} e^{-r_{s}} \\
{\left[-e^{-\alpha_{1} \beta t_{s}}+e^{-\left(r+\alpha_{2} \beta\right)\left(L-t_{s}\right)-\alpha_{1} \beta t_{s}}\right.} \\
\left.+1-e^{-\left(r+\alpha_{2} \beta\right) L}\right]
\end{gathered}
$$

(b) The optimal strategy is to launch immediately. $w^{*}=0$, whenever $A e^{-a x} \geq B+e^{-(a+b) x}$, where $x=\max \left\{0, t_{s}-L\right\}$, and

$$
\begin{gathered}
\frac{\alpha_{1}}{\left(r+\alpha_{1} \beta\right)}\left[1-e^{-\left(r+\alpha_{1} \beta\right) t_{s}}\right] \\
\geq \frac{\alpha_{2}}{\left(r+\alpha_{2} \beta\right)} e^{-r_{s}} \\
{\left[-e^{-\alpha_{1} \beta t_{s}}+e^{-\left(r+\alpha_{2} \beta\right)\left(L-t_{s}\right)-\alpha_{1} \beta t_{s}}\right.} \\
\left.+1-e^{-\left(r+\alpha_{2} \beta\right) L}\right]
\end{gathered}
$$

Corollary 1: (a) For a sufficiently large $L, w^{*}=0$.

(b) For a sufficiently large $t_{s}, w^{*}=0$.

Greater sales during the season, a longer life, a closer season, and a larger tail all favor waiting for the season. Greater discount rates and a weaker season both favor launching immediately.

\section{The Diffusion Model}

Beyond the exponential model, another example for $S(t)$ is the classic diffusion model for new durables and some repeat purchase items (Blattberg 1991; Mahajan, Muller, and Bass 1990):

$$
S_{T}(T)=\frac{m p(q+p)^{2} e^{-(p+q) T}}{\left[p+q e^{-(p+q) T}\right]^{2}}
$$

where $p, q$, and $m$ are constants and $m=\lim Y(t)$ As with the exponential model, $m$ represents the $\stackrel{t \rightarrow \infty}{\text { eventual cumula- }}$ tive sales (Bass, Krishnan, and Jain 1994). As is illustrated previously, the time-transformation method does not require this specific $S(t)$.

We model $\mathrm{p}, \mathrm{q}$, and $\mathrm{m}$ as constants and not as functions of when the new product is launched. The shape of the sales 
curve in observed time, however, will vary according to when the product is launched. For example, diffusion occurs more rapidly and the product enjoys more sales (during L) when launched in the high season compared with the low season. This assumption is violated when seasonality is not captured fully by transformed time or when the time of the launch influences the seasonal pattern. For example, a bad durable product released during the high season might generate large sales during the first week before negative word of mouth destroys future sales. That product might have a smaller $m$ during the off-season because negative word of mouth occurs before some buyers are fooled into buying the product. Therefore, the underlying diffusion model becomes misspecified and our transformation can not correct it. In this article, we do not explicitly consider word-of-mouth effects and assume the sales function is well specified.

Using Equation 11, we obtain Equation 12:

$$
S(t)=f^{\prime}(t) \frac{m p(q+p)^{2} e^{-(p+q) f(t)}}{\left[p+q e^{-(p+q) f(t)}\right]^{2}}
$$

Equation 12 provides the seasonal diffusion model in observed time. Here, $p, q$, and $m$ retain their original interpretations. Without seasonality, $g(t)$ is constant, $f(t)=t$, and Equation 12 reduces to Equation 11 .

Equation 12 is similar to the equation estimated by Bass, Krishnan, and Jain (1994). They derive Equation 12 as a general method for including marketing mix variables in diffusion models. With marketing mix variables for $\mathrm{f}(\mathrm{t})$, rather than seasonality, they find the model fits historical data very well. Some researchers estimate diffusion models using years of annual data to avoid monthly seasons. Using known seasonality enables estimation in less than one year by using weekly or monthly data.

\section{The Optimal Wait}

The optimal strategy for the exponential model is usually to either wait until the high season or launch immediately. For the diffusion model, however, intermediate waits can be optimal because they exhibit an initial period of growth. It is sometimes best to have that growth occur in the low season. The distributor should launch shortly before the high season and start the diffusion process so that peak sales occur in the peak season. The support for this result lies in the shape of the curve. As the tail of the exponential model enters the season, each one-day additional delay brings increasing sales into the season. Consequently, the optimal solution is to push all sales into the high season or launch immediately.

In the growth phase of the diffusion model, the opposite may be true. Early sales can be small before sales reach their peak. By waiting another day, a smaller number of incremental sales might be pushed into the season than would be during the previous day. A long wait has less advantage than a shorter wait because the long wait pushes the majority of sales into the future without a commensurate gain.

Although we can calculate the exact optimal wait, mathematical complexity prevents the derivation of direct strategic implications. Fortunately, the sufficient conditions in Theorem 6 provide the optimal strategy for products with diffusion sales patterns for any seasonal pattern $g(t)$ :
Theorem 6: Let $h(p, q, L)=e^{-(p+q) f(L)}-e^{-(p+q) f_{w}(L)}$. Then.

(a) if $e^{r(L+w)}<I+h(p, q, L)$, waiting (i.e., $w^{*}=t_{s}$ ) is optimal and

(b) if $\mathrm{e}^{r(L-w)}<1-h(p, q, L)$, launching immediately (i.e., $w^{*}=0$ ) is optimal.

Theorem 6 suggests that increases in $r$ favor an immediate launch.

\section{The Impact of $p$ and $q$}

Now we consider the effect of the diffusion parameters on the launch decision. When the life of the product is less than the waiting period, we obtain Theorem 7:

Theorem 7: Let $X$ be such that $1-e^{r(L-w)}+e^{-X f_{w}(L)}=e^{-X f(L)}$, and let $Y$ be such that $1-e^{r(L+w)}+e^{-Y f(L)}=$

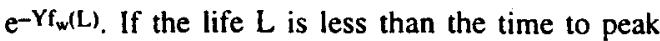
season $t_{s}$, then

(a) for $p+q<X$, launching immediately is optimal and

(b) for $p+q>Y$, launching immediately is optimal.

Theorem 7 reveals some interesting tendencies. Both a large and a small $p+q$ favor launching immediately. Intermediate values, however, might suggest waiting. Figure 5 provides the support.

A small $p+q$ yields slow growth whenever we launch. Although waiting provides somewhat higher sales, the discount rate favors launching immediately. A large $p+q$ yields rapid growth. The growth is so rapid that the product completes much of its life in the low season. Waiting provides few incremental sales. An intermediate $p+q$ yields an intermediate growth rate. The product is unable to complete the rapid stage of its life cycle during the low season. Waiting so that some sales are in the high season allows accelerated growth, and the product completes this rapid stage. Therefore, waiting is optimal. Our results for $p+q$ therefore are analogous to our results for $\beta$ for the exponential model.

\section{THE IMPACT OF THE PRODUCT LIFE}

We now consider how the new product's life affects launching when a product is ready directly after the peak of the high season. For example, we let $w=6$ and use the $f(t)$ in Table 2. We define $f_{w}(L)=f(L+w)-f(w)=f(L+6)-$ $f(6)$. We now can compute $f(L)$ and compare it with $f_{w}(L)$. We find that the optimal strategy cycles. For a short life, we should launch immediately. For longer lives, we should wait until the next season. Even longer lives favor an immediate launch.

To understand the effect of $L$ on launching strategy, recall the nature of the wait. Here, the season peaks at month 0 when $g(t)=2$. The product is ready directly after the peak, that is, $g(t)=1.8660$. Consider a wait until the start of the next season, which occurs at month 6 , when $g(t)=0$. Launching immediately yields the tail end of the season. Waiting yields the entire next season.

For short lives, we launch immediately because $\Delta(\mathrm{L})=$ $f(L+w)-f(w)-f(L)<0$. A short life captures sufficient sales in the remaining season to make waiting undesirable. Slightly longer lives $(8 \leq \mathrm{L} \leq 11)$ make waiting desirable because $\Delta(\mathrm{L})>0$. Here, the life is sufficiently long so that the remaining sales during this season are smaller than potential sales in the subsequent high season. Even longer lives $(12 \leq$ $\mathrm{L} \leq 24$ ) make launching optimal because $\Delta(\mathrm{L})<0$. For a sufficiently long life, an immediate launch captures both the re- 
mainder of this season and the growth period of the subsequent season. Note that the seasonal pattern in our example is complex. Actual seasonal patterns may be simpler. For very simple constant high then constant low seasonal patterns, the optimal wait may depend less on $\mathrm{L}$.

\section{APPLICATIONS TO MOTION PICTURES}

Our empirical application examines the film industry. We estimate $f(t)$ for domestic films. This section supplies the needed information to deseasonalize film data and provides implications for prediction. In addition, we check our theorems on timing releases against actual studio decisions, using both the exponential and the diffusion model. Our strategic implications should provide useful support. For specific recommendations for a particular film, we also could use specific parameter estimates (e.g., $\beta$ ).

Without historical data, studios can learn parameter ranges from test screens (Eliashberg and Sawhney 1994). Tests are becoming common and can reveal the general magnitude of required parameters. Tests for the film Speed, for example, revealed a surprisingly positive word of mouth, so the studio changed the introduction date. Other options include early critic reviews (Eliashberg and Shugan 1997), success of prior films involving the people making the current film (Shugan 1997), and moviegoers' stated intent (Shugan and Swait 1997).

Similar to other industries, movie box office sales are highly seasonal. For example, the diffusion of the films $A n$ American Tail and Black Robe shows the influence of each holiday season (see Figure 6). Oscar nominations can exaggerate box office sales around President's Day (see Dodds and Holbrook 1988). We assume this seasonality is exogenous and beyond a single film's control. Some films may be sufficiently popular to change the seasonal pattern itself.

We gathered data for all major films released between July 2, 1993 and July 13,1995. Our data came from Variety and Daily Variety, which report data from Baseline Inc. and Entertainment Data Incorporated (owned by ACNielsen). Our database examined releases of 673 films (more than 6000 observations). We obtained complete screen and box office data for 636 films and had the com- plete life cycle for 505 films during the 106 weeks. The number of films per week usually ranged from 58 to 60 . Ranking films by box office sales reveals that the bottom films account for few sales. Variety reported, for example, 60 films for the first week in July. Of those, the top 40 films accounted for $99.39 \%$ of the total box office. Therefore, our data represent nearly complete box office totals.

We estimated the seasonal pattern for total box office. Although 52 different levels of seasonality ( 1 for each week) are possible, trade publications suggest specific seasonal patterns. For example, spring is one season but Memorial Day differs. Starting with these priors, we refined the model with actual data. Our final model found the 12 levels of weekly seasonality shown in Figure 7. Each bar shows estimated seasonality for one week. All 12 levels were significant (see Table 3). With $N=106$, the adjusted multiple $R^{2}$ $=.985$ and $F=573$. Finally, we use the same weeks as $V a$ riety, starting on Fridays. The first week in January was $12 / 31$ to $1 / 6$ for 1994 and $12 / 30$ to $1 / 5$ for 1995 . Pictures released on 12/31 are classified as December releases. This seasonal pattern allows deseasonalizing the box office sales of any film. The pattern alters the shape of the diffusion for films launched in different seasons. We also fit the model with a trend. The deseasonalized trend was insignificant $(t=$ .978 and $p=.330$ ), despite movie industry claims that the box office is slowly growing.

Equation 13 provides the discrete version of Equation 1. Equation 13 and $g(t)$ in Table 3 provide $f(t)$. The seasonal cycle is 52 weeks ( 1 year). At the end of the cycle, $t=f(t)=$ 52 , and the cycle repeats (see Table 4):

$$
f(t)=52 \frac{\sum_{i=1}^{t} g(i)}{\sum_{k=1}^{52} g(k)}
$$

Most distributors believe that peak seasons bring increased competition, because industry wisdom suggests that many firms launch new products in the peak season. There is, however, evidence that competitive movies can expand the market, encouraging peak season entry. For example, the motion picture Independence Day (ID4)

Figure 6

HOLIDAY SEASON EFFECTS

\section{Black Robe}

\section{Box Office}

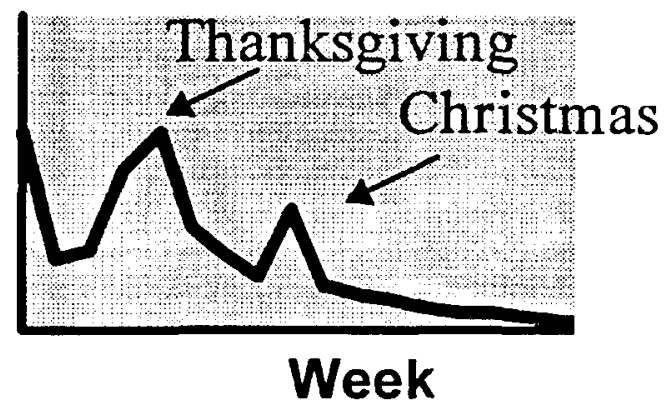

\section{American Tail}

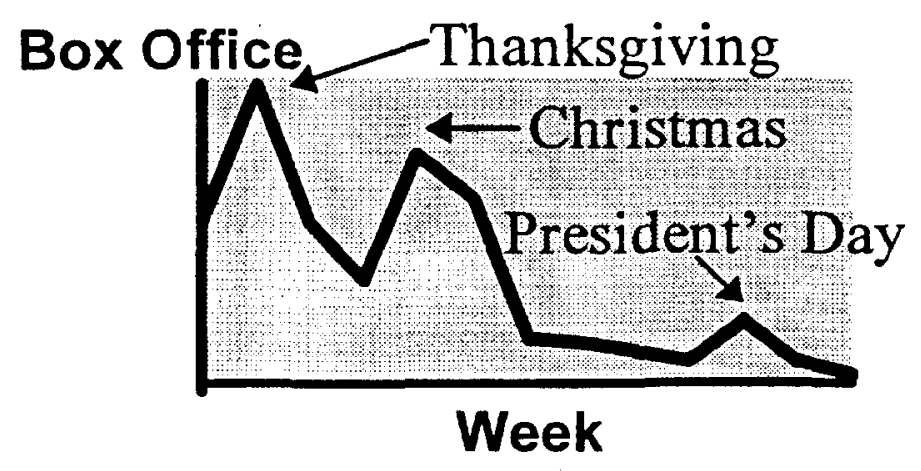


enhanced the box office for competitive films because. unable to get tickets for $1 D 4$, moviegoers opted to attend another movie (Mcnary 1996).

Table 5 shows average monthly seasonality. We obtain average seasonality by averaging the seasonality for each week in the month (from Table 3). For our 106 weeks of data, 505 films completed their life, L. The average $\mathrm{L}$ was 9.618 weeks, with a standard deviation of 7.539 . Although lives varied by month, differences were insignificant. Further research on this topic is necessary, but our fixed life assumption appears to be a good approximation.
Perhaps increased competition during the high season shortens film lives. To check this hypothesis, we regressed the life of the film on the season released. We found an insignificant relationship $\left(\mathrm{N}=505\right.$, adjusted $\left.\mathrm{R}^{2}=.0, \mathrm{t}=.747\right)$.

We also investigated the impact of seasonality on the average monthly box office (see Table 5). Although June was not the highest season, it enjoyed the largest mean box office from $\$ 100+$ million films, such as Batman Forever, Speed. and The Lion King. In general, however, box office was related to average seasonality. Regressing ultimate cumulative box office on seasonality indicated that seasonali-

Figure 7

WEEKLY SEASONALITY LEVELS

\section{Box Office}

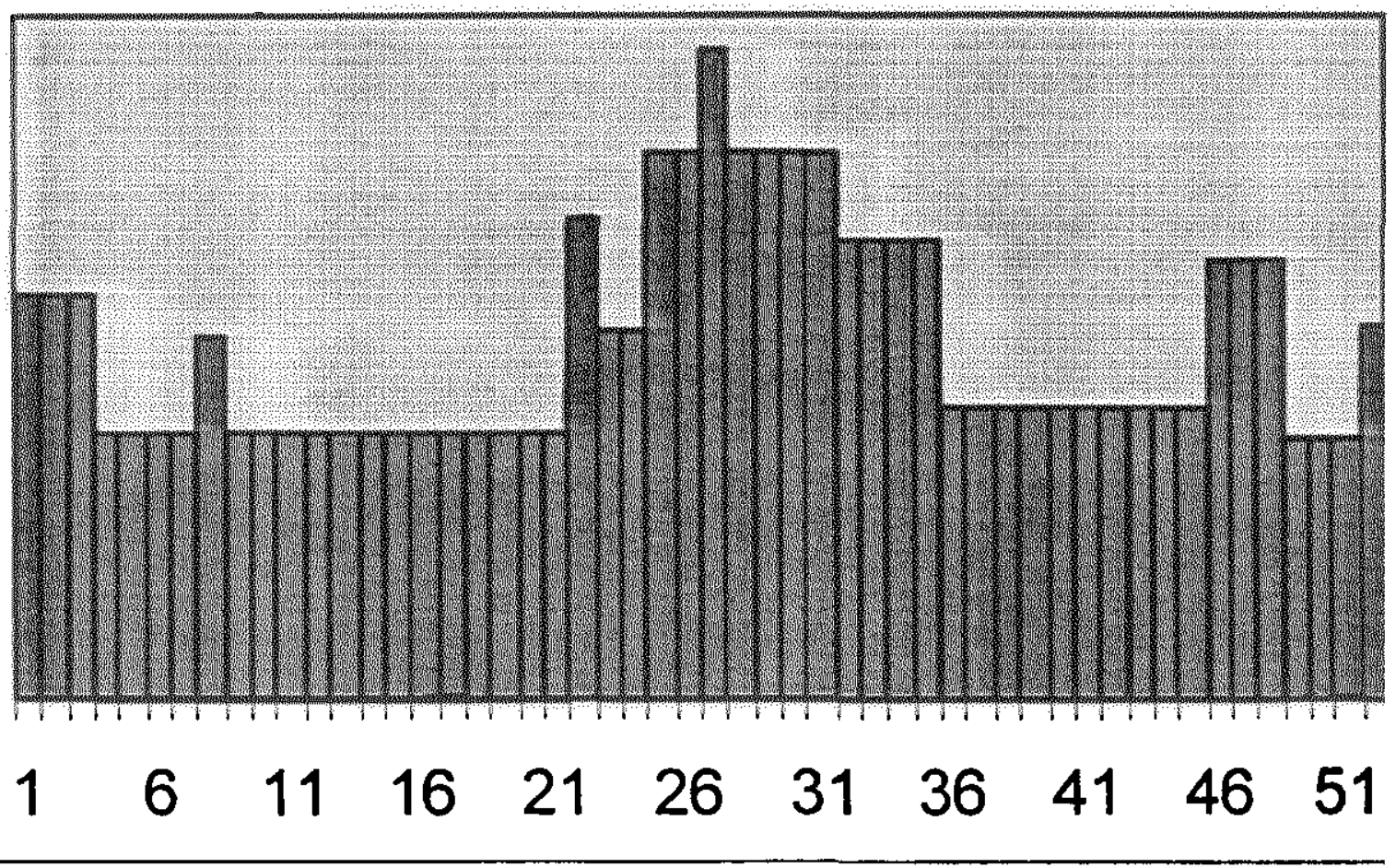

Table 3

ESTIMATED SEASONAL PATTERN FOR MOTION PICTURES

\begin{tabular}{|c|c|c|c|}
\hline Season & Time & $g(t)$ in 000 's & $t$ \\
\hline I & January (first 3 weeks) & 109,954 & $21.228^{*}$ \\
\hline 2 & Next 19 weeks (except President's Day) & 73,268 & 33.672* \\
\hline 3 & $\begin{array}{l}\text { President's Day } \\
\end{array}$ & 98,340 & $10.961^{*}$ \\
\hline 5 & June (first 2 weeks) & 99.656 & $15.709^{*}$ \\
\hline 6 & Next 6 weeks (except Independence Day) & 147.603 & $41.945^{*}$ \\
\hline 7 & Independence Day & 175,227 & $23.921^{*}$ \\
\hline 11 & December (first 3 weeks) & 70,654 & $13.640^{*}$ \\
\hline 12 & Christmas Week & 101,861 & $11.354^{*}$ \\
\hline
\end{tabular}

*Significant at $<.001$. 
Table 4

ESTIMATED WEEKLY $f(t)$ FOR MOTION PICTURES

\begin{tabular}{|c|c|c|c|c|c|c|c|c|c|}
\hline$t$ & $f(t)$ & $t$ & $f(t)$ & $t$ & $f(t)$ & $t$ & $f(t)$ & $t$ & $f(t)$ \\
\hline l & 1.139 & 12 & 10.507 & 23 & 19.719 & 33 & 34.299 & 43 & 43.406 \\
\hline 2 & 2.278 & 13 & 11.266 & 24 & 20.752 & 34 & 35.579 & 44 & 44.225 \\
\hline 3 & 3.417 & 14 & 12.025 & 25 & 22.281 & 35 & 36.858 & 45 & 45.043 \\
\hline 5 & 4.935 & 16 & 13.543 & 27 & 25.625 & 37 & 38.495 & 47 & 47.514 \\
\hline 6 & 5.694 & 17 & 14.301 & 28 & 27.153 & 38 & 39.314 & 48 & 48.749 \\
\hline 7 & 6.453 & 18 & 15.060 & 29 & 28.682 & 39 & 40.132 & 49 & 49.481 \\
\hline 11 & 9.748 & 22 & 18.687 & & & & & & \\
\hline
\end{tabular}

Table 5

FILM LIVES/RELEASES BY MONTH

\begin{tabular}{|c|c|c|c|c|c|c|}
\hline Month & $\begin{array}{c}\text { Average } \\
\text { Life } \\
\text { (in Weeks) }\end{array}$ & $\begin{array}{c}\text { Average } \\
\text { Seasonality }\end{array}$ & $\begin{array}{l}\text { Mean } \\
\text { Box } \\
\text { Office }\end{array}$ & $\begin{array}{c}\text { Number of } \\
\text { Releases } \\
\text { over } 106 \text { weeks }\end{array}$ & $\begin{array}{l}\text { Average } \\
\text { Releases } \\
\text { per Week }\end{array}$ & Screens \\
\hline January & 7.6 & $9,527,900$ & $9,475,230$ & 35 & 4.4 & 26,254 \\
\hline March & 9.3 & $7,326,800$ & $11,679.643$ & 41 & 5.1 & 30.464 \\
\hline Aprii & 8.5 & $7,326,800$ & $9.640,275$ & 73 & 8.1 & 30,294 \\
\hline May & 8.8 & $8,753,200$ & $11,964,197$ & 38 & 4.2 & 29.054 \\
\hline June & 9.5 & $12,363,000$ & $38,603,951$ & 56 & 4.7 & 27,432 \\
\hline September & 9.7 & $7,902,000$ & $11,456.617$ & 76 & 10.8 & 25,363 \\
\hline October & 9.8 & $7,902,000$ & $10,964,857$ & 61 & 6.8 & 25,877 \\
\hline November & 11.0 & $10,920,200$ & $24,618,442$ & 48 & 6.0 & 28,831 \\
\hline December & 12.4 & $7,845,600$ & $22,939,199$ & 66 & 6.6 & 30,826 \\
\hline Average & 9.6 & $9,745,770$ & $16,366,956$ & 56 & 6.3 & 29.407 \\
\hline Standard Deviation & 7.5 & & & & & \\
\hline
\end{tabular}

ty was significant $\left(N=12\right.$, adjusted $\left.R^{2}=.866, t=8.447\right)$. This finding is consistent with our theory about time moving faster. One month during the peak season can generate the sales of several months off-season.

Finally, we tested the fixed $\mathrm{m}$ assumption. Were $\mathrm{m}$ fixed, an increase in opening screens, controlling for opening box office, would only shift sales from future weeks to the opening week, creating a negative relationship between cumulative box office, $m$, and opening screens. Regressing opening screens on cumulative box office, controlling for opening box office, reveals a significant negative relationship $(\mathbf{N}=$ 3688 , adjusted $\mathrm{R}^{2}=.531, \mathrm{t}=-10.138, p=.000$ ).

We now use $f(t)$ to ascertain the consistency of our key theorems on timing releases with our data. Timing releases for seasonal introduction is common in the film industry. Movie studios influence timing by scheduling production, but schedules are not perfectly predictable. This creates dilemmas regarding when to launch. To check our theorems, we estimate the appropriate model (i.e., exponential or Bass) for movies introduced at the beginning of the low season, that is, March. Our theorems predict whether waiting or launching is optimal. For movies released in March, our theorems should predict an immediate launch because the studio has not waited for Memorial Day. We now check the consistency of theorems with studio decisions. Note that our purpose here is not box office prediction. We address that issue subsequently.
We found 31 films released in March with sufficiently long lives ( 3 weeks) to estimate a model for sales. We use the respective theorems, depending on the model estimated, to make predictions. Our predictions were consistent with studio decisions for 27 of the 31 films (87\%) (see Table 6). We estimated $p+q$ with constrained nonlinear regression. Logical consistency requires $p+q>0$ and $m>y(L)$. We set the initial parameter values so that the sales curve passed through the points $1, \mathrm{~L} / 2$, and $\mathrm{L}$ in transformed time. When the algorithm failed to converge, we kept these values.

Our predictions are inconsistent with studio decisions for several films, such as China Moon. We predict that the studio should have waited until Memorial Day rather than launching in March. In these cases, either the studio made a mistake or there are other important factors that the theorem overlooks. A review of available information revealed no special factors for these movies.

Although our data do not allow a direct test of Theorem 7 , the theorem suggests that the variance for $p+q$ might be greater farther from the peak season because only films with extreme values of $p+q$ are released. Films with average values of $p+q$ wait and thereby decrease the variance of $p+q$ during the peak season.

We compared the standard deviation for $p+q$ during two months requiring long waits, March and September, to the beginning of their respective seasons, May and November. The standard deviations were greater, but the difference was 
statistically insignificant. It is possible that the peak season variance in $\mathrm{p}+\mathrm{q}$ is sufficientiy great that adding several average values fails to decrease it significantly. We did find, however, that the range of $p+q$ in the low season $(.015$ to 1.187) was larger than the range in the high season $(.007$ to 1.030), as was predicted by Theorem 7 .

Table 5 shows releases by month for all films, including those with short lives (i.e., no estimated $p+q$ ) and those with missing box office data. As was predicted by Corollary 1, many releases occur when the wait is long (e.g., April, September), and few releases occur when the wait is short (e.g., November). High seasons (e.g., July, August) have many releases compared with low seasons (e.g., May). January and April are indeterminate.

We also correlated screens with releases. August averaged 36,271 screens per week, whereas September averaged 25,363 . The distribution channel accommodates more films during the peak season. Perhaps this "added shelf space" results from more showings per day.

Finally, we examined the ability of the transformed-time model to estimate diffusion with fewer data points and to provide earlier forecasts. We return to the films Naked in New York and Picture Bride. Table 7 shows the actual box office returns for the two films for the first ten weeks after their release. Using the first five weeks of data, we estimated the original (observed time) and the transformed-time diffusion models. Table 7 shows $\mathrm{p}, \mathrm{q}$, and $\mathrm{m}$ for both models of both films. The table also compares model fit for the first five weeks and the predictive accuracy for the subsequent five weeks.
After using the first five weeks to estimate $p$ and $q$ in transformed time, Equation 14 provides predicted sales in observed time using the transformed-time model:

$$
s(t)=[f(t)-f(t-1)]\left(p+\frac{q y(t)}{m}\right)[m-y(t)] .
$$

The transformed-time model for Naked in New York fits the first five observations better and provides much better predictions for the last five observations (correlation $=.951$ ) than the regular diffusion model does (correlation $=.766$ ). The transformed time model for Picture Bride also fits the first five observations better and provides much better predictions for the last five observations (correlation $=.952$ ) than the regular diffusion model does (correlation $=.797$ ). The transformed-time model captures the effect of Memorial Day, whereas the regular diffusion model does not. As Figure 8 illustrates, Memorial Day significantly distorts the growth of both films in observed time.

The solid lines in Figure 8 show the actual box office returns for Naked in New York and Picture Bride. The dotted lines show the diffusion model predictions, whereas the dashed lines show the transformed-time model predictions. We see that adjusting for seasonality better captures the peaks in box office. Finally, recall that the transformed-time diffusion model reduces to the regular diffusion model in periods in which no seasonal changes occur. Both models therefore should perform similarly under those circumstances.

Table 6

THEOREM 2 PREDICTIONS ON WHEN TO LAUNCH

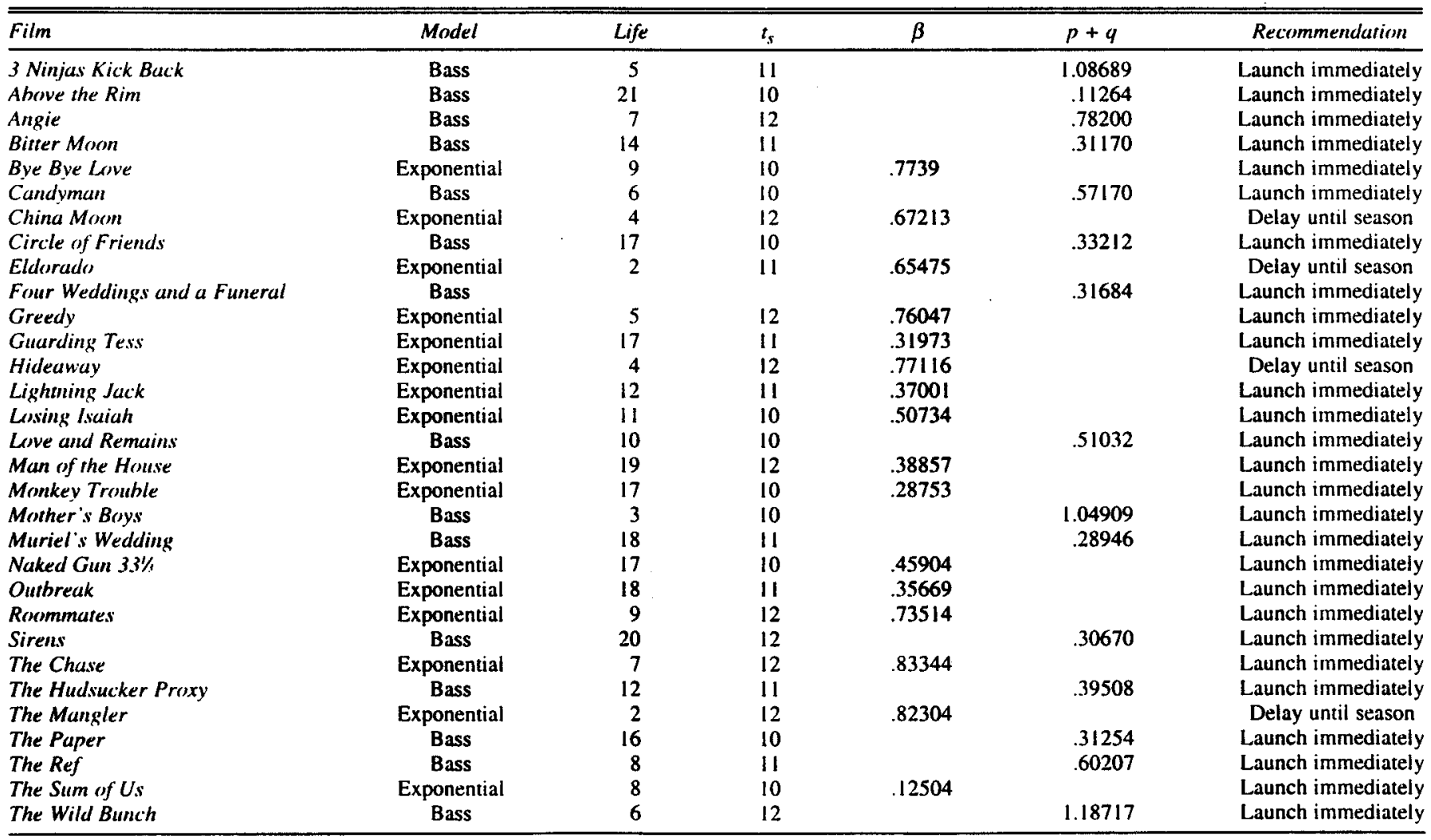


Table 7

PREDICTIONS FOR TWO FILMS

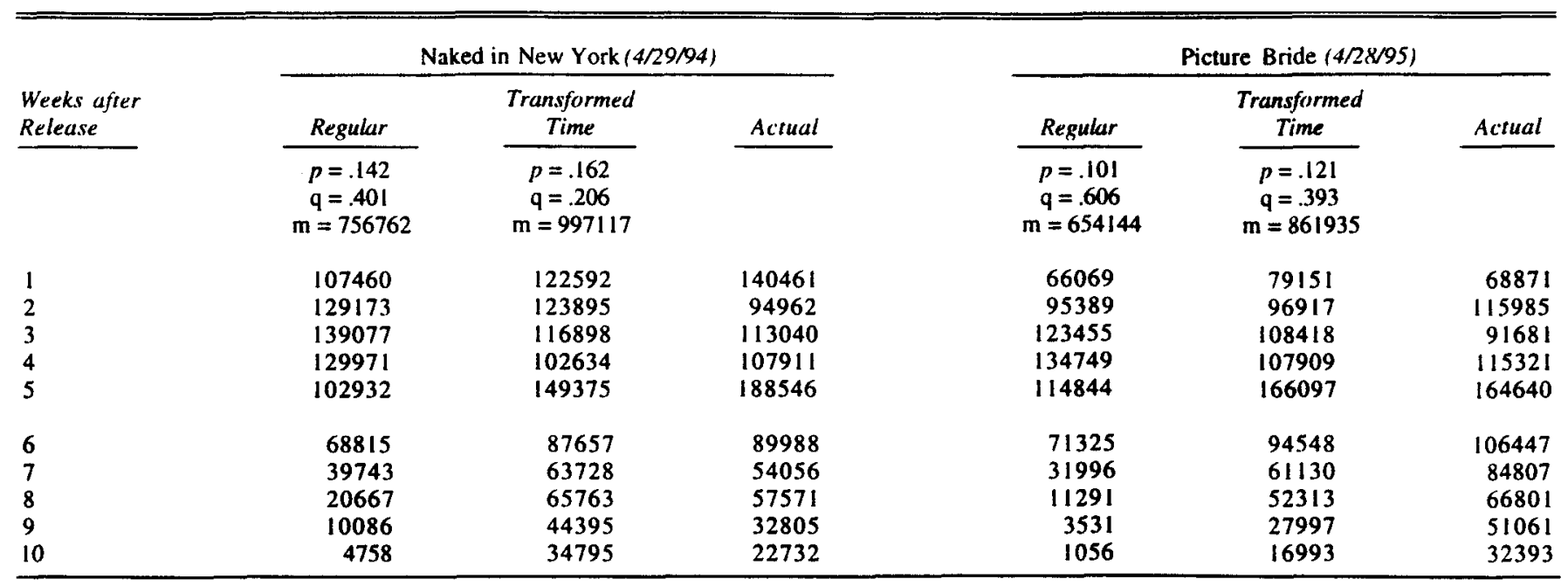

\section{SUMMARY AND FURTHER RESEARCH}

Nearly every product displays some seasonality. The objective of this article was to make a first attempt at providing a theoretical foundation for modeling seasonality and illustrate its usefulness in strategy formulation. We transformed time so that during high seasons, time moves faster than observed time. During the low seasons, time moves more slowly. At the end of each seasonal cycle, transformed time and observed time equate.

Our transformed-time method goes beyond adjusting sales for seasonality. Our method accelerates and decelerates the product's aging along its life cycle for high and low seasons, respectively. Our method also enables us to incorporate known exogenous seasonal patterns into any dynamic model parsimoniously, without changing the foundation of the original underlying model. By viewing the model in transformed time, we remain loyal to the original model's assumptions and interpretation. Beyond adjusting for seasonal demand, we also speed or slow the product's aging along its life cycle. The high season speeds aging.

As an example, we used the transformed-time method to develop seasonal versions of both the exponential and Bass diffusion model. By considering seasonality, we find insights into several important problems, including the timing of new product introductions and whether to launch in a current low season or wait for the next high season.

We find that the shape of the life cycle is important for timing strategy. We show that when the sales of a new product are decreasing continuously (i.e., a typical pattern for single-purchase products such as motion pictures), we should either launch immediately or wait until the high season. In contrast, when sales grow, stabilize, and then decline, an intermediate wait is possible. In this case, we can time a product's introduction so that growth begins in the off-season but the majority of sales occur at the beginning of the peak season. This strategy moves sales forward while allowing the product to enjoy a boost from the peak season. We identify specific conditions in which different strategies are optimum.
We also find that the early growth rate influences the optimal wait. Very rapid or very slow growth in the off-season encourages an immediate launch because waiting for the season has little impact. When growth is intermediate, however, the season can affect sales significantly. Here, waiting might be the optimal strategy.

Finally, the length of the product's life is also important. When we are just past the peak of the season, a short life suggests launching immediately, because the short life catches the end of the season. A long life also suggests launching immediately, because the product lasts into the next high season. An intermediate life suggests waiting; the optimal wait depends on the length of the life. Generally, the longer the life, the shorter the optimal wait.

Our empirical work compares our theoretical results with empirical observations in the movie industry. As with most industries, we found that movies are highly seasonal. We derived the seasonal pattern for the industry for 106 weeks, gathering more than 6000 observations. We found 12 different levels of seasonality. With them, we found $g(t)$ and $f(t)$, which enabled us to derive monthly seasonality and better examine competition between films.

Consistent with our fixed life assumption, our data indicate that film lives are as long during the peak season as during the off-season. As was expected, the average box office is higher for films released in the high season. However, the box office performance of many films in the low season exceeded the average film.

We also compare the predictions of our theorems on waiting with actual studio behavior. We found that Theorems 5 and 6 predicted $87 \%$ of the films in our analysis, consistent with studio decisions. In the other cases, either the studio made a mistake or there were other important factors that the theorem overlooked. A review of available information revealed no special factors for these movies.

Our test of Theorem 7 was mixed. The signs were correct, but the magnitudes were insignificant. Finally, we checked the prediction capabilities of the seasonal model with two films: Naked in New York and Picture Bride. In both cases, the seasonal model performed well. 
Despite these interesting results, there are many directions for further research. We must test predictability in other product categories. The analysis could include marketing mix variables (Jeuland 1981) and competitive reaction. Krider and Weinberg (1998), for example, suggest that some films that are unable to withstand the peak season competition during the off-peak season should be launched.

Additional theoretical research also might explore other seasonal patterns, the effect of seasonality on other managerial decisions, the precise role of word of mouth, optimal advertising given seasonal and intertemporal influences, and finally, channel relationships. During the high seasons, distributors have de trop films to exhibit, whereas the low season brings scarcity.

\section{APPENDIX}

\section{Proof of Theorem I}

We assume that initial sales are greater than the cutoff $\mathrm{c}$ (otherwise the product does not get launched at all). We equate the discounted sales to $\mathrm{c}$ and solve for life $\mathrm{L}$. We want to solve $e^{-\pi} S_{w}(L)=c$, where $t$ is time since the product was finished, that is, $t=L+w$, and $S_{w}$ denotes sales starting from $t=w$ (product is launched at $t=w$ ). In other words, we need to solve

$$
e^{-r(L+w)} S_{w}(L)=c .
$$

Note that $S_{w}(t)=S\left[f_{w}(t)\right]$.
Case I

Assume that $w<t_{s}$. First, we compute the time $\ell$ that the sales would need to drop to cutoff $\mathrm{c}$ if there was no imminent high season. Here, $f_{w}(t)=\alpha_{1} t-\alpha_{1} w$. Now we have

$$
\mathrm{e}^{-r(f+w)} \mathrm{S}_{w}(\ell)=\mathrm{e}^{-r(\ell+w) y e-\beta \alpha \alpha_{1}(\ell+w-w)}=c .
$$

After taking logarithm of both sides and solving for $\mathrm{L}$, we get

$$
\ell=\frac{\ln \left(\frac{\gamma}{c}\right)-r w}{r+\alpha_{1} \beta}
$$

Because the product starts diffusing at $t=w$, if $\{[\ln (\gamma / c)-$ $\left.\mathrm{rw}] /\left[\mathrm{r}+\alpha_{1} \beta\right]\right]<\mathrm{t}_{\mathrm{s}}-\mathrm{w}$, the entire life of the product is completed in the low season, and $L=\ell=\{[\ln (\gamma / \mathrm{c})-\mathrm{rw}] /[\mathrm{r}+$ $\left.\left.\alpha_{1} \beta\right]\right\}$. If $\left\{[\ln (\gamma / c)-r w] /\left[r+\alpha_{1} \beta\right]\right\}>t_{s}-w$, the product will run into the high season because it cannot complete its life in the low season. Therefore, the time $f_{w}(t)$ becomes $f_{w}(t)=$ $\left(\alpha_{1}-\alpha_{2}\right) t_{s}+\alpha_{2} t-\alpha_{1} w$. This implies that

$$
e^{-r(L+w)} S_{w}(L)=e^{-r(L+w) y e-\beta\left[\left(\alpha_{1}-\alpha_{2}\right) L_{s}+\alpha_{2}(L+w)-\alpha_{1} w\right] .}
$$

To find $L$, we must solve the equation $e^{-r(L+w)} S_{w}(L)=c$; that is, the equation

$$
\mathrm{e}^{-r(L+w) y e-\beta\left[\left(\alpha_{1}-\alpha_{2}\right) t_{s}+\alpha_{2}(L+w)-\alpha_{1} w\right]}=c .
$$

\section{Naked in New York}

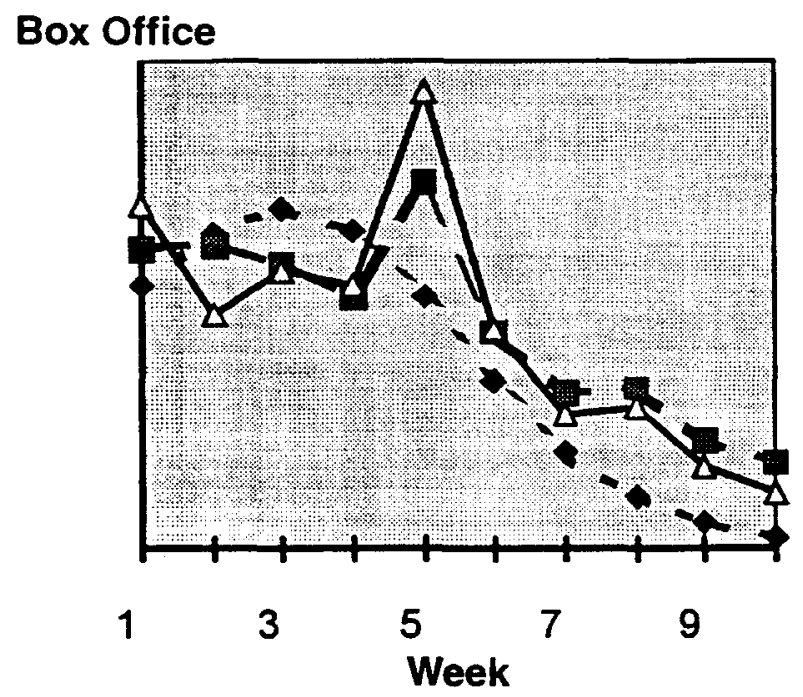

\section{Picture Bride}

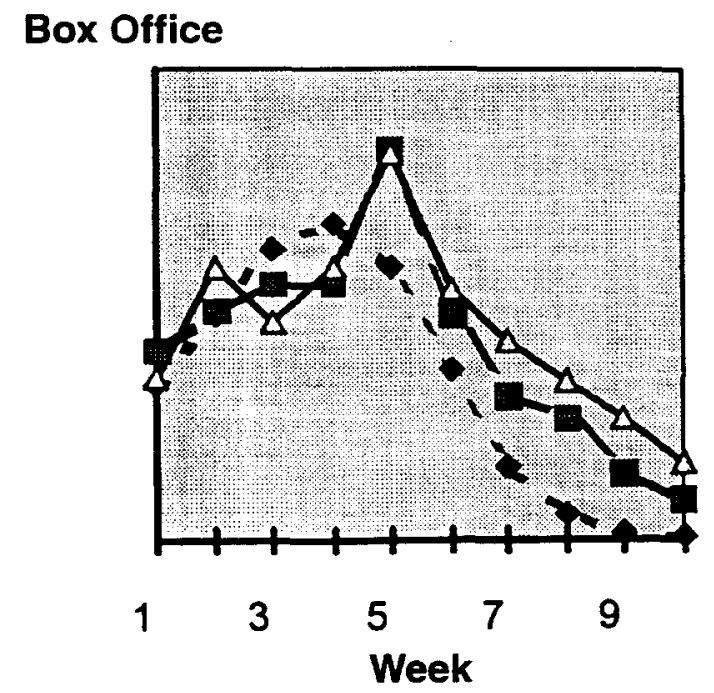

$$
\begin{aligned}
& \text { Key: } \\
& \begin{aligned}
\Delta & =\text { transformed time } \\
\Delta & =\text { actual } \\
& =\text { regular }
\end{aligned}
\end{aligned}
$$


We take logarithm of both sides of the equation and solve for L. Finally, we get

$$
\mathrm{L}=\frac{\ln \frac{\gamma}{\mathrm{c}}+\beta\left(\alpha_{2}-\alpha_{1}\right)\left(\mathrm{t}_{\mathrm{s}}-\mathrm{w}\right)-\mathrm{rw}}{\mathrm{r}+\beta \alpha_{2}} .
$$

This $\mathrm{L}$ is the product's life.

\section{Case 2}

If $w \geq t_{s}$, then $f_{w}(t)=\alpha_{2}(t-w)$ and the equation $e^{-r(L+}$ w) $S_{w}(L)=c$ becomes

$$
e^{-r\left(L+w h y e-\beta \alpha_{2}[(L+w)-w]\right.}=c .
$$

We take logarithm of both sides and solve for $\mathrm{L}$. We obtain

$$
L=\frac{\ln \left(\frac{\gamma}{c}\right)-r w}{r+\alpha_{2} \beta} .
$$

This $\mathrm{L}$ is the product's life.

\section{PROOF OF THEOREM 2}

By $\pi$, we denote the profit function. We analyze three cases, namely, when the product is released so that the tail remains completely in the low season $\left(w<t_{s}\right.$ and $\left.L<t_{s}-w\right)$, when the sales happen entirely in the high season $\left(w>t_{s}\right)$, and the mixed case when the product is launched in the low season, but the tail enters the high season $\left(w<t_{s}\right.$ and $L>t_{s}$ $-w)$.

We will prove that $\pi$ always decreases with waiting. In the rest of this proof, profit function is given by

$$
\pi(w)=\int_{0}^{L} e^{-r(h+w)} S_{w}(h) d h-C .
$$

In this formula, $\mathrm{h}$ stands for time elapsed since the launch. To simplify the ensuing computations, we use $t=h+w$ instead of $h$ (i.e., we consider the time elapsed since the product was finished, rather than time elapsed since the product was launched). With this convention, we claim that

$$
\begin{aligned}
\pi(w) & =\int_{0}^{L} e^{-r(h+w)} S_{w}(h) d h-C \\
& =\int_{0}^{L} e^{-r(h+w)} S[f(h+w)-f(w)] d h-C \\
& =\int_{w}^{L+w} e^{-r r} S[f(t)-f(w)] d t-C .
\end{aligned}
$$

Case I

If $w<t_{s}$ and $\left\{[\ln (\gamma / c)-r w] /\left[r+\alpha_{1} \beta\right]\right\}<t_{s}-w$, then the product completes its life in the low season. The profit function $\pi$ is given by

$$
\begin{aligned}
\pi(w) & =\int_{w}^{L+w} e^{-r t} S[f(t)-f(w)] d t-C \\
& =\gamma \int_{w}^{L+w} e^{-r t f_{w}^{\prime}(t) e^{-\beta f_{w}(t)} d t-C} \\
& =\gamma \int_{w}^{L+w} e^{-r t} \alpha_{1} e^{-\beta \alpha_{1}(t-w)} d t-C \\
& =\alpha_{1} \gamma e^{\alpha_{1} \beta w} \frac{e^{-\left(r+\alpha_{1} \beta\right) w}-e^{-\left(r+\alpha_{1} \beta\right)(L+w)}}{r+\alpha_{1} \beta}-C .
\end{aligned}
$$

Now we compute $d \pi / d w$. After simplifying, we get

$$
\begin{aligned}
& \frac{d \pi}{d w}=\alpha_{1} \gamma e^{\alpha_{1} \beta w} {\left[-r \frac{e^{-\left(r+\alpha_{1} \beta\right) w}-e^{-\left(r+\alpha_{1} \beta\right)(L+w)}}{r+\alpha_{1} \beta}\right.} \\
&\left.-r \frac{e^{\left.-\left(r+\alpha_{1} \beta\right) L+w\right)}}{r+\alpha_{1} \beta}\right] .
\end{aligned}
$$

From this, we find that $d \pi / d w<0$; thus, profits are declining with waiting.

\section{Case 2}

If $w<t_{s}$ and $\left\{[\ln (\gamma / c)-r w] /\left[r+\alpha_{1} \beta\right]\right\} \geq t_{s}-w$, then the product's life is

$$
L=\frac{\frac{\gamma}{c}+\beta\left(\alpha_{2}-\alpha_{1}\right)\left(t_{s}-w\right)-r w}{r+\beta \alpha_{2}}>t_{s}-w .
$$

This inequality is true because $\left\{[(\gamma / c)-r w] /\left[r+\alpha_{1} \beta\right]\right\} \geq$ $\left\{[\ln (\gamma / c)-r w] /\left[r+\alpha_{1} \beta\right]\right\} \geq t_{s}-w$, by assumption. This implies that $\left\{[(\gamma / c)-r w] /\left[r+\alpha_{2} \beta\right]\right\} \geq\left(t_{s}-w\right)\left(r+\alpha_{1} \beta\right) /(r+$ $\left.\alpha_{2} \beta\right)$. It is easy to verify that this is equivalent to $L \geq t_{s}-w$.

From $f_{w}(h)$, we deduce that $f(t)-f(w)=\left(\alpha_{1}-\alpha_{2}\right) t_{s}+\alpha_{2} t$ $-\alpha_{1} w$, and therefore, profit function is equal to

$$
\begin{aligned}
& \pi(w)=\int_{w}^{t_{s}} e^{-r} S[f(t)-f(w)] d t \\
& +\int_{t_{s}}^{L+w} e^{-r t S}[f(t)-f(w)] d t-C \\
& =\gamma \int_{w}^{t_{s}} e^{-r t} \alpha_{1} e-\beta \alpha_{1}(t-w) d t \\
& +\gamma \int_{t_{s}}^{L+w} e^{-\pi} \alpha_{2} e^{-\beta\left[\alpha_{2} l+\left(\alpha_{1}-\alpha_{2}\right) t_{s}-\alpha_{1} w\right] d t}-C \\
& =\frac{\alpha_{1} \gamma}{r+\alpha_{1} \beta} e^{\alpha_{1} \beta w}\left[e^{-\left(r+\alpha_{1} \beta\right) w}-e^{-\left(r+\alpha_{t} \beta\right) t_{s}}\right] \\
& +\frac{\alpha_{2} \gamma e^{-\beta\left[\left(\alpha_{1}-\alpha_{2}\right) \gamma_{s}-\alpha_{1} w\right]}}{r+\alpha_{2} \beta} \\
& {\left[e^{-\left(r+\alpha_{2} \beta\right) t_{s}}-e^{-\left(r+\alpha_{2} \beta\right)(L+w)}\right]-C .}
\end{aligned}
$$

After further simplification, we obtain

$$
\begin{aligned}
& \pi(w)=\gamma e^{\beta} \beta \alpha_{1} w\left\{\frac { \alpha _ { 1 } } { r + \alpha _ { 1 } \beta } \left[e^{-\left(r+\alpha_{1} \beta\right) w}-e^{\left.-\left(r+\alpha_{1} \beta\right) t_{s}\right]}+\frac{\alpha_{2}}{r+\alpha_{2} \beta}\right.\right. \\
& \left.\mathrm{e}^{-\left(\mathrm{r}+\alpha_{1} \beta\right) \mathrm{t}_{\mathrm{s}}}\right\}-\gamma \mathrm{e}^{\beta \alpha_{1} w} \frac{\alpha_{2} \mathrm{e}^{-\beta\left(\alpha_{1}-\alpha_{2}\right)_{\mathrm{s}}} \mathrm{e}^{-\left(\mathrm{r}+\alpha_{1} \beta\right)}(\mathrm{L}+\mathrm{w})}{\mathrm{r}+\alpha_{2} \beta}-\mathrm{C} \text {. }
\end{aligned}
$$

After differentiating profit function with respect to delay $w$ and simplifying, we get

$$
\frac{\mathrm{d} \pi}{\mathrm{dw}}=\frac{\gamma r \alpha_{1} \mathrm{e}^{-\mathrm{rw}}}{r+\alpha_{1} \beta}\left[-1+\frac{\beta \mathrm{e}^{-\left(r+\alpha_{1} \beta \mathrm{t}_{\mathrm{s}}-w\right)}\left(\alpha_{2}-\alpha_{1}\right)}{r+\alpha_{2} \beta}\right]-\frac{\mathrm{dK}}{\mathrm{dw}},
$$

where we define $\mathrm{K}$ as 


$$
K=\frac{\gamma \alpha_{2} e^{-\left(\alpha_{1}-\alpha_{2}\right) \beta t_{s}}}{r+\alpha_{2} \beta} e^{\beta \alpha_{1} w-\left(r+\alpha_{2} \beta\right)(L+w)} .
$$

Because $d L / d w=\left\{\left[\left(\alpha_{1}-\alpha_{2}\right) \beta-r\right] /\left[r+\alpha_{2} \beta\right]\right\}$, when we compute $\mathrm{dK} / \mathrm{dw}$ and substitute the previous expression for $d L / d w$, we get $d K / d w=0$. Therefore,

$$
\frac{d \pi}{d w}=\frac{r r \alpha_{1} e^{-r w}}{r+\alpha_{1} \beta}\left[-1+\frac{\beta e^{-\left(r+\alpha_{1} \beta\right)\left(t_{s}-w\right)}\left(\alpha_{2}-\alpha_{1}\right)}{r+\alpha_{2} \beta}\right] .
$$

We prove next that

$$
-1+\frac{\beta \mathrm{e}^{\left.-\left(\mathrm{r}+\alpha_{1} \beta\right) \mathrm{t}_{\mathrm{s}}-w\right)}\left(\alpha_{2}-\alpha_{1}\right)}{r+\alpha_{2} \beta}<0 .
$$

We assume the contrary, that is, that this expression is greater than or equal to zero. This would imply that

$$
e^{-\left(r+\alpha_{1} \beta k_{s}-w\right)} \geq \frac{r+\alpha_{2} \beta}{\beta\left(\alpha_{2}-\alpha_{1}\right)} .
$$

The right-hand side of this inequality is greater than $1(\mathrm{r}+$ $\alpha_{2} \beta>\beta \alpha_{2}-\alpha_{1} \beta$ is equivalent to $r+\alpha_{1} \beta>0$ ), whereas the left-hand side of the inequality is less than 1 (because $w<$ $t_{s}$ ). This is a contradiction; thus

$$
-1+\frac{\beta e^{-\left(r+\alpha_{1} \beta \mathrm{t}_{\mathrm{s}}-w\right)}\left(\alpha_{2}-\alpha_{1}\right)}{\mathrm{r}+\alpha_{2} \beta}<0,
$$

which in turn implies that $\mathrm{d} \pi / \mathrm{dw}<0$, or profits are declining with waiting.

Case 3

If $w \geq t_{s}$, then the product's life is

$$
L=\frac{\ln \left(\frac{\gamma}{c}\right)-r w}{r+\alpha, \beta} .
$$

Because $f_{w}(t)=\alpha_{2}(t-w)$, the profit function can be expressed as

$$
\begin{aligned}
\pi(w) & =\int_{w}^{L+w} e^{-\pi S}[f(t)-f(w)] d t-C \\
& =\gamma \int_{w}^{L+w} e^{-\pi f f^{\gamma}}{ }_{w}(t) e^{-\beta f_{w}(t)} d t-C \\
& =\gamma \int_{w}^{L+w} e^{-r \alpha_{2} e^{-\beta\left[\alpha_{2}(t-w)\right]} d t-C} \\
& \left.=\frac{\gamma \alpha_{2} e^{\beta \alpha_{2} w}}{r+\alpha_{2} \beta}\left[e^{-\left(r+\alpha_{2} \beta\right) w}-e^{-\left(r+\alpha_{2} \beta\right) L}+w /\right)\right]-C .
\end{aligned}
$$

After taking the derivative $d \pi / d w$ and substituting $d L / d w=$ $\left(-r / r+\alpha_{2} \beta\right)$, we obtain

$$
\begin{aligned}
\frac{d \pi}{d w}= & \gamma \alpha_{2} e^{\beta \alpha_{2} w}\left[-e^{\left(r+\alpha_{2} \beta\right) w}+e^{\left(r+\alpha_{2} \beta h L+w\right)}\right. \\
& \left.+e^{\left(r+\alpha_{2} \beta\right)(L+w)} \frac{-r}{r+\alpha_{2} \beta}\right] .
\end{aligned}
$$

We find that $d \pi / d w<0$; therefore, profits are declining with waiting. All three cases together cover the entire range of possible situations. In all of them, profits decline with waiting. Therefore, an immediate launch is the optimal strategy.

\section{PROOF OF THEOREM 4}

The function $d \Pi / d w=e^{-a x}\left(e^{-b x}-A\right)+B$ can be written as $\Pi^{\prime}(x)=q(x)+B$, where $q(x)=e^{-a x}\left(e^{-b x}-A\right), a=a_{1}=r$ $+\alpha_{1} \beta, b=a_{2}-a_{1}=\beta\left(\alpha_{2}-\alpha_{1}\right), A=T e^{a_{2} L} e^{\left(a_{1}-a_{2}\right) l_{s} a_{2}, B=}$ $T e^{a_{2}}\left(L-L_{5}\right)\left(a_{2}-a_{1}\right)$, and $T=\left[\alpha_{1} r / \alpha_{2} a_{1}\left(r+a_{2}-a_{1}\right)\right]$. We observe $\Pi$ on $\left(0, t_{s}\right)$ if $L \geq t_{s}$, and $\left(t_{s}-L, t_{s}\right)$ if $L<t_{s}$. We want to determine relative maximum of $\Pi$. To do this, we investigate $q(x)$. Note that

$$
q^{\prime}(x)=e^{-b x-a x}(-a-b)-e^{-a x} A(-a)=e^{-a x}\left[-(a+b) e^{-b x}+a A\right] .
$$

If $-(a+b)+a A \geq 0$, then $q^{\prime}(x) \geq 0$, which implies that $\mathrm{d} \Pi / \mathrm{dw} \geq 0$, and thus, $\Pi$ is increasing.

If $-(a+b)+a A<0$, there is a unique zero of $q^{\prime}(x)$, which we denote by $x^{*}$, and this $x^{*}$ is the unique relative minimum of $q(x)$, thus a unique relative minimum of $d \Pi / d w$. To find $x^{*}$, we must solve the equation $-e^{-b x^{*}}(a+b)+a A=0$. Thus $-b x^{*}=\ln [a A /(a+b)]$, which implies that

$$
x^{*}=\frac{-1}{b} \ln \left(\frac{a A}{a+b}\right)=\frac{-1}{\left(a_{2}-a_{1}\right)} \ln \left(\frac{a_{1} A}{a_{2}}\right) .
$$

Note that $\Pi$ has a relative maximum iff $d \Pi / d w$ changes from positive to negative. If $\mathrm{d} \Pi / \mathrm{dw}\left(\mathrm{x}^{*}\right) \geq 0$, then $\mathrm{d} \Pi / \mathrm{dw}$ is always positive (because its minimum is a positive number). In this case, $\Pi$ is always increasing and does not have a relative maximum. Therefore, $\Pi$ has relative maximum only if $\mathrm{d} \Pi / \mathrm{d} w\left(\mathrm{x}^{*}\right)<0$, that is, if $\mathrm{q}\left(\mathrm{x}^{*}\right)+\mathrm{B}<0$.

We observe function $\Pi$ only from $y=\max \left\{0, t_{s}-L\right\}$ to $t_{s}$. If $d \Pi / d w(y)<0$, then $d \Pi / d w$ does not have relative maximum (because the only possible change of sign is from negative to positive). This presents us with the second condition for relative maximum of $\Pi$, namely $d \Pi / d w(y)>0$. Therefore, $\Pi$ achieves relative maximum on $(0, y)$ only if both $\mathrm{d} \Pi / \mathrm{dw}\left(\mathrm{x}^{*}\right)<0$ and $\mathrm{d} \Pi / \mathrm{dw}(\mathrm{y})>0$ are true. In the rest of this proof, we examine both conditions.

First condition. We start with $\mathrm{d} \Pi / \mathrm{dw}\left(\mathrm{x}^{*}\right)<0$. As we mentioned previously, this condition is equivalent to $q\left(x^{*}\right)$ $+\mathrm{B}<0$. Taking into consideration the formula for $\mathrm{x}^{*}$, we demonstrate that

$$
q\left(x^{*}\right)+B<0 \text { is equivalent to } e^{-a_{1} x^{*}} \frac{\left(a_{2}-a_{1}\right) A}{a_{2}}>B \text {. }
$$

This implies that $e^{-a_{1} x^{*}}\left[\left(a_{2}-a_{1}\right) / a_{2}\right] A>B$, which, after simplification, becomes $e^{a_{1}\left(t_{s}-x^{*}\right)}>1$. This in turn implies that $t_{\mathrm{s}}>\mathrm{x}^{*}$. Using the expression for $\mathrm{x}^{*}$ computed previously, we obtain

$$
\frac{-1}{a_{2}-a_{1}} \ln \left[\frac{a_{1} T e^{a_{2} L_{e}\left(a_{1}-a_{2}\right) t_{s} a_{2}}}{a_{2}}\right]<t_{s} .
$$

We can simplify this inequality further, until we obtain

$$
\ln a_{1}+a_{2} L>\ln T^{-1}=\ln \left[\frac{\alpha_{2} a_{1}\left(r+a_{2}-a_{1}\right)}{\alpha_{1} r}\right] .
$$

Now we have proved that

$$
q\left(x^{*}\right)+B<0 \Leftrightarrow \ln \left[\frac{\alpha_{2} a_{1}\left(r+a_{2}-a_{1}\right)}{\alpha_{1} r}\right]<a_{2} L+\ln a_{1} .
$$

Second condition. Next we look at the second condition, $\mathrm{d} \Pi / \mathrm{dw}(\mathrm{y})>0$. Here, $y$ changes depending on the relation- 
ship between $L$ and $t_{s}$ (as we mentioned previously, $L>t_{s}$ implies $\mathrm{y}=0$, and $\mathrm{L} \leq \mathrm{t}_{\mathrm{s}}$ implies $\mathrm{y}=\mathrm{t}_{\mathrm{s}}-\mathrm{L}$ ). Therefore, we must study these cases separately.

Assume $L>t_{s}$. Then $y=0$ and, thus, $d \Pi / d w(y)>0$ becomes $\mathrm{d} \Pi / \mathrm{dw}(0)=q(0)+\mathrm{B}>0$. This is equivalent to $\mathrm{A}<\mathrm{B}$ +1 . Substituting expressions for $A$ and $B$ in this inequality, we obtain

$$
T e^{a_{2}} L_{e}\left(a_{1}-a_{2}\right) t_{s} a_{2}<T e^{a_{2}}\left(L-t_{s}\right)\left(a_{2}-a_{1}\right)+1 .
$$

After taking the in of both sides and further simplifying, we obtain

$$
\ln \left[\frac{\alpha_{2} a_{1}\left(r+a_{2}-a_{1}\right)}{\alpha_{1} r}\right]>a_{2}\left(L-t_{s}\right)+\ln \left[e^{a_{1}} k_{s_{2}}-\left(a_{2}-a_{1}\right) \mid .\right.
$$

Assume $\mathrm{L} \leq \mathrm{t}_{\mathrm{s}}$. Then $\mathrm{y}=\mathrm{t}_{\mathrm{s}}-\mathrm{L}$ and, thus, $\mathrm{d} \Pi / \mathrm{dw}(\mathrm{y})>0$ becomes $d \Pi / d w\left(t_{s}-L\right)=q\left(t_{s}-L\right)+B>0$. This is equivalent to

$$
e^{-a_{1}(t s-L)}\left[e^{-\left(a_{2}-a_{1}\right)\left(t_{s}-L\right)}-A\right]+B>0 .
$$

Again, after substituting expressions for A and B and further simplifying, we obtain

$$
\ln \left[\frac{\alpha_{2} a_{1}\left(r+a_{2}-a_{1}\right)}{\alpha_{1} r}\right]>\ln \left|e^{a_{1}} L_{a_{2}}-\left(a_{2}-a_{1}\right)\right| .
$$

This analysis gives us sufficient and necessary conditions for $\Pi$ to reach relative maximum on $\left(y, t_{s}\right)$, where $y=\max \{0$, $\left.t_{s}-L\right\}$. We summarize it as follows:

(1) If $L \geq t_{s}$, then $\Pi$ has a relative maximum on $\left(0, t_{s}\right)$ iff

$$
\begin{aligned}
a_{2} L+\ln a_{1}> & \ln \left[\frac{\alpha_{2} a_{1}\left(r+a_{2}-a_{1}\right)}{\alpha_{1} r}\right]>a_{2}\left(L-t_{s}\right) \\
& +\ln \left[e^{a_{1} k_{k} a_{2}}-\left(a_{2}-a_{1}\right)\right] .
\end{aligned}
$$

(2) If $L<t_{s}$, then $\Pi$ has a relative maximum in $\left(t_{s}-L, t_{s}\right)$ iff

$$
a_{2} L+\ln a_{1}>\ln \left[\frac{\alpha_{2} a_{1}\left(r+a_{2}-a_{1}\right)}{\alpha_{1} r}\right]>\ln \left[e^{\left.a_{1} t_{k} a_{2}-\left(a_{2}-a_{1}\right)\right] .}\right.
$$

\section{PROOF OF THEOREM 6}

We must compare $\int_{0}^{L} e^{-r t S}(t) d t$ with $\int_{0}^{L} e^{-r(t+w)} S_{w}(t) d t$. By $\mathrm{D}$ we denote the difference of these two integrals, namely,

$$
\begin{aligned}
D & =\int_{0}^{L} e^{-r} S(t) d t-\int_{0}^{L} e^{-r(t+w)} S_{w}(t) d t \\
& =e^{-r L Y} Y(L)+r \int_{0}^{L} e^{-r t Y(t) d t}-e^{-r(L+w)} Y_{1}(L) \\
& -r \int_{0}^{L} e^{-r(t+w)} Y_{w}(t) d t .
\end{aligned}
$$

Because both $Y$ and $Y_{1}$ are increasing, we can estimate $D$ as follows:

$$
e^{-r L} Y(L)-e^{-r w} Y_{w}(L)<D<Y(L)-e^{-r(L+w)} Y_{w}(L) .
$$

If $Y(L)-e^{-r(L+w)} Y_{w}(L)<0$, then $D<0$. This means that the second integral in $\mathrm{D}$ is larger, and it is better to delay the launch. If $\mathrm{e}^{-\mathrm{rL}} \mathrm{Y}(\mathrm{L})-\mathrm{e}^{-\mathrm{rw}} \mathrm{Y}_{\mathrm{w}}(\mathrm{L})>0$, then $\mathrm{D}>0$. This means that the first integral in $\mathrm{D}$ is bigger, and therefore, an immediate launch is a better strategy.

Recall that

$$
\begin{aligned}
Y(t) & =m p \frac{\left[1-e^{-(p+q) f(t)}\right]}{\left[p+q e^{-(p+q) f(t)}\right]}, \\
Y_{w}(t) & =m p \frac{\left[1-e^{-(p+q) f_{w}(t)}\right]}{\left[p+q e^{-(p+q) f_{w}(t)}\right]} .
\end{aligned}
$$

Because formulae for $\mathrm{Y}$ and $\mathrm{Y}_{\mathrm{w}}$ are complicated, we now discuss two particular cases in which it is easier to determine the course of action. For the sake of simplicity, we write $E=e^{-(p+q) f(t)}$ and $F=e^{-(p+q)\left[f_{w}(t)-f(t)\right]}$.

\section{Case 1}

Assume that $e^{r(L+w)}-1<E(1-F)$. Then, $e^{r(L+w)}-1<$ $E(1-F) /(1-E)$. This implies that $e^{r(L+w)}<E(1-F) /(1-$ E) $+1<1+(p+q) E(1-F) /[(p+q)(1-E)]<1+(p+q) E(1$ $-F) /[(p+q E F)(1-E)]=(p+q E)(1-E F) /[(p+q E F)(1-$

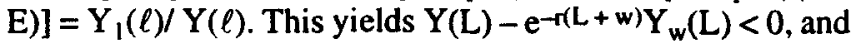
therefore, $\mathrm{D}<0$.

\section{Case 2}

Assume that $\mathrm{e}^{\mathrm{r}(L-w)}-1<\mathrm{E}(\mathrm{F}-1)$. Then, $\mathrm{e}^{\mathrm{r}(\mathrm{L}-w)}<1+$ $(p+q) E(F-1) /[(p+q E)(1-E F)]=(1-E)(p+q E F) /[(p+$ $q E)(1-E F)]=Y(L) / Y_{w}(L)$. This implies that $e^{-r L Y}(L)-$ $e^{-r w} Y_{w}(L)>0$, and therefore, $D>0$.

\section{PROOF OF THEOREM 7}

Let $G_{1}$ be defined in the following way: $G_{1}(x)=1+$ $e^{-x f_{w}(L)}-e^{-x f(L)}-e^{r(L-w)}$, where $x=p+q$. We can rewrite this as $G_{1}(x)=K+e^{-x f_{w}(L)}-e^{-x f(L)}$, where $K=1-e^{r(L-w)}$. Because $f_{w}(L)>f(L)$, the two functions $K+e^{-x f_{w}(L)}$ and $e^{-x f(L)}$ intersect only once, at point $x_{1}{ }^{*}$. For $x<x_{1}{ }^{*}$, we have $K+e^{-x f_{w}(L)}>e^{-x f(L)}$, and for $x>x_{1}^{*}$ this changes to $K+$ $\mathrm{e}^{-x f_{w}(L)}<\mathrm{e}^{-x f(L)}$. Therefore $G_{1}(x)>0$ for all $x<x_{1}{ }^{*}$, and $G_{1}(x)<0$ for all $x>x_{1}{ }^{*}$. Note that $G_{l}(x)>0$ is equivalent to Part $b$ of Theorem 6; therefore, if $x<x_{1}{ }^{*}$, it is best to launch immediately.

Let $G_{2}$ be defined in the following way: $G_{2}(x)=1-$ $e^{-x f_{w}(L)}+e^{-x f(L)}-e^{r(L+w)}$, where $x=p+q$. We can rewrite this as $G_{2}(x)=C+e^{-x f(L)}-e^{-x f_{w}(L)}$, where $C=1-e^{r(L+w)}$. Because $C<0$, and $f_{w}(L)>f(L)$, we find that the two functions $K+e^{-x f(L)}$ and $e^{-x f_{w}(L)}$ intersect only once, at point $x_{2}{ }^{*}$. For $x<x_{2}{ }^{*}$ we have $K+e^{-x f(L)}<e^{-x f_{w}(L)}$, and for $x>x_{2}{ }^{*}$ we have $K+e^{-x f(L)}>e^{-x f_{w}(L)}$. Therefore, $G_{2}(x)<0$ for all $x$ $<x_{2}{ }^{*}$, and $G_{2}(x)>0$ for all $x>x_{2}{ }^{*}$. Note that $G_{2}(x)>0$ is equivalent to Part a of Theorem 6; therefore, if $x>x_{2}{ }^{*}$, it is best to delay the launch until $t_{s}$.

We show next that $x_{1}{ }^{*}<x_{2}{ }^{*}$. Assume that this is not true, namely, that $x_{1}{ }^{*}>x_{2}{ }^{*}$. Then $G_{2}\left(x_{1}{ }^{*}\right)>0$, and so $x_{1}{ }^{*}$ satisfies both Parts $a$ and $b$ of Theorem 6 , which is not possible. Therefore $x_{1}{ }^{*}<x_{2} *$.

Finally, we find that when $x<x_{1}^{*}$ (small $x$ ) or $x>$ $x_{2} *(\operatorname{large} x)$, it is best to launch immediately.

\section{REFERENCES}

Bass, Frank, Trichy Krishnan, and Dipak Jain (1994), "Why the Bass Model Fits Without Decision Variables," Marketing Science, 13 (Summer), 203-23.

Blattberg, Robert C. (1991), "Behavioral Research in the 1990s," Management \& Applications, 3 (Summer), 3, 12.

Dodds, J.C. and M.B. Holbrook (1988), "What's an Oscar Worth? An Empirical Estimation of the Effect of Nominations and 
Awards on Movie Distribution and Revenues." in Current Research in Film: Audiences, Economics, and Law, Vol. 4, B.A. Austin, ed. Norwood, NJ: Ablex Publishing Co., 72-88.

Eliashberg, Jehoshua and Mohanbir S. Sawhney (1994), "Modeling Goes to Hollywood: Predicting Individual Differences in Movie Enjoyment," Management Science, 40 (September), $1151-73$.

and Steven Shugan (1997), "Film Critics: Influencers or Predictors?" Journal of Marketing, 61 (April), 68-78.

Jeuland, Abel (1981), "Parsimonious Models of Diffusion of Innovation-Part B: Incorporating the Variable Price," working paper, University of Chicago.

King, Doreen (1992), "Chocs Away: Boxed Chocolate Mints Industry," Industry Overview, 1022 (May), 28.

Krider, Robert E. and Charles B. Weinberg (1998), "Competitive Dynamics and the Introduction of New Products: The Motion Picture Timing Game," Journal of Marketing Research, forthcoming. Mahajan, V., E. Muller, and F. Bass (1990), "New Product Diffusion Models in Marketing: A Review and Directions for Future Research," Journal of Marketing, 54 (January), 1-26.
McMath, Robert (1994), "Product Proliferation: New Brands and Brand Extensions Released in 1994," Mediaweek, 4 (October 17), S34.

Mcnary, Dave (1996), "Independence Day Posts Huge 2nd Day," Hollywood Regional News, (July 4).

Schrage, Michael (1986), "Publishers Fear Book May Close on Tax Guides," The Washington Post, (June 24).

Sehlinger, Bob (1995), The Unofficial Guide to Walt Disney World \& Epcot. New York: Prentice Hall Travel.

Shugan, Steven (1997), "Forecasting New Product Success Before the Concept: Applications to Motion Pictures," working paper. Department of Marketing, University of Florida.

- and Joffre Swait (1997), "Translating Purchase Intent to Sales: Applications to Motion Pictures," working paper, Department of Marketing, University of Florida.

Ulmer, James (1994), “Bond's 'Golden Eye' Blinks, Delays Production," The Hollywood Reporter, (August 3).

Zellner, A., ed. (1979), NBER-Census Conference on Seasonal Economic Time Series. Washington, DC: Government Printing Office. 